\title{
Chapter 7. Pharmaceuticals and personal care products (PPCPs) in the environment and their removal from wastewater through constructed wetlands
}

Cristina Ávila and Joan García

GEMMA - Group of Environmental Engineering and Microbiology, Department of Hydraulic, Maritime and Environmental Engineering, Universitat Politècnica de Catalunya-BarcelonaTech, c/ Jordi Girona 1-3, Building D1, E-08034, Barcelona, Spain 


\section{Chapter outline}

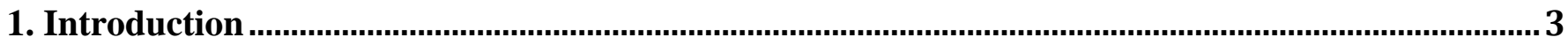

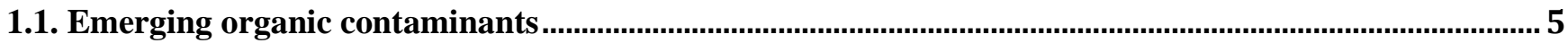

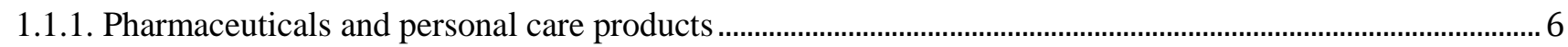

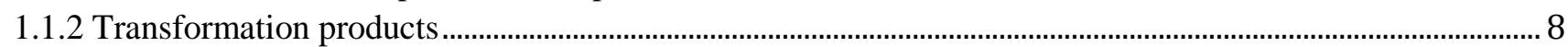

1.2. Sources and fate of pharmaceuticals and personal care products in the environment........................... 8

1.3. Toxicity and evaluation of risks associated to pharmaceuticals and personal care products................ 11

1.4. Occurrence and fate of pharmaceuticals and personal care products in conventional wastewater

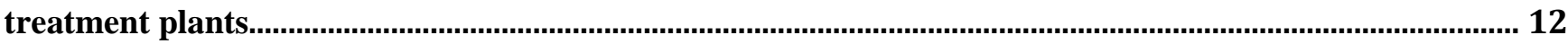

1.5. Removal of pharmaceuticals and personal care products through tertiary and advanced treatment

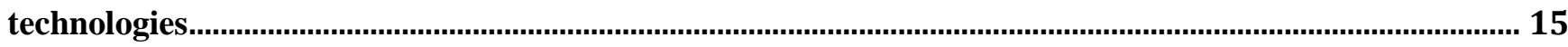

2. Constructed wetlands: a decentralized wastewater treatment ecotechnology ............................... 17

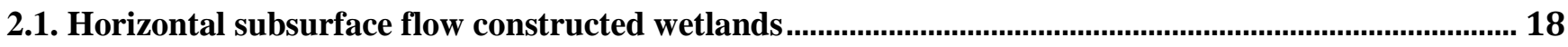

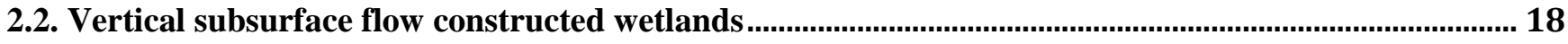

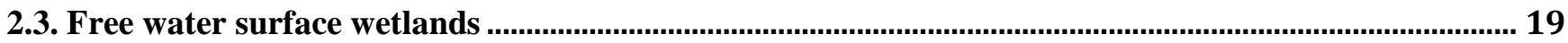

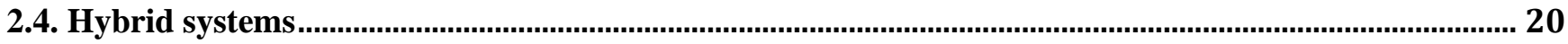

3. Removal and behavior of pharmaceuticals and personal care products in constructed wetlands

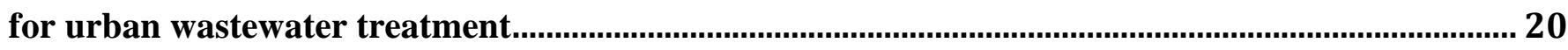

3.1. Design and operational factors affecting the removal of pharmaceuticals and personal care products

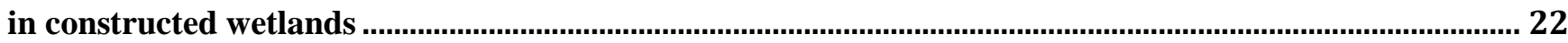

3.1.1. Behavior of PPCPs in horizontal subsurface flow constructed wetlands .................................................... 22

3.1.2. Behavior of PPCPs in vertical subsurface flow constructed wetlands........................................................... 24

3.2. Behavior of pharmaceuticals and personal care products in hybrid constructed wetland systems...... 25

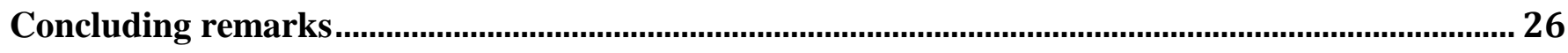

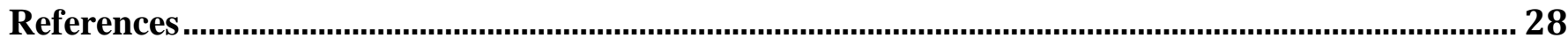




\section{Introduction}

Water scarcity forces people to rely on unsafe sources of drinking water. The use of poor water quality can increase the risk of waterborne diseases (e.g. cholera, typhoid fever, etc.). Every year almost 2 million child deaths are counted related to unclean water and poor sanitation (UNDP, 2006).

Although Millenium Development Goal (MDG) number 7 aims to halve by 2015 the proportion of people without sustainable access to safe drinking water and basic sanitation, the situation is getting worse. Water scarcity is an increasing problem, as needs for water rise along with population growth, urbanization and higher industrial and domestic water demand. On national and local scales, there is a need for appropriately funded infrastructure and robust governance mechanisms in order to protect water resources and ensure a sustainable development and distribution of water-derived benefits. Initiatives are emerging worldwide to attain this matter. For that reason, wastewater treatment, reuse and reclamation represent key practices in that approach (UNESCO, 2012).

More than one-third of the planet's accessible renewable freshwater is used for agricultural, industrial and municipal purposes. Most of the activities eventually lead to the contamination of freshwater systems worldwide with thousands of industrial and natural chemical compounds. Some 2 million tons of waste, derived from all industrial and human activities (e.g. synthetic compounds used in industrial and consumer products; diffuse agricultural pollution from the application of fertilizers and pesticides; oil and gasoline components through accidental spills, etc.) are released into receiving waters everyday with incomplete or no treatment at all (Fig. 1.1) (UNESCO, 2003; Schwarzenbach et al., 2006).

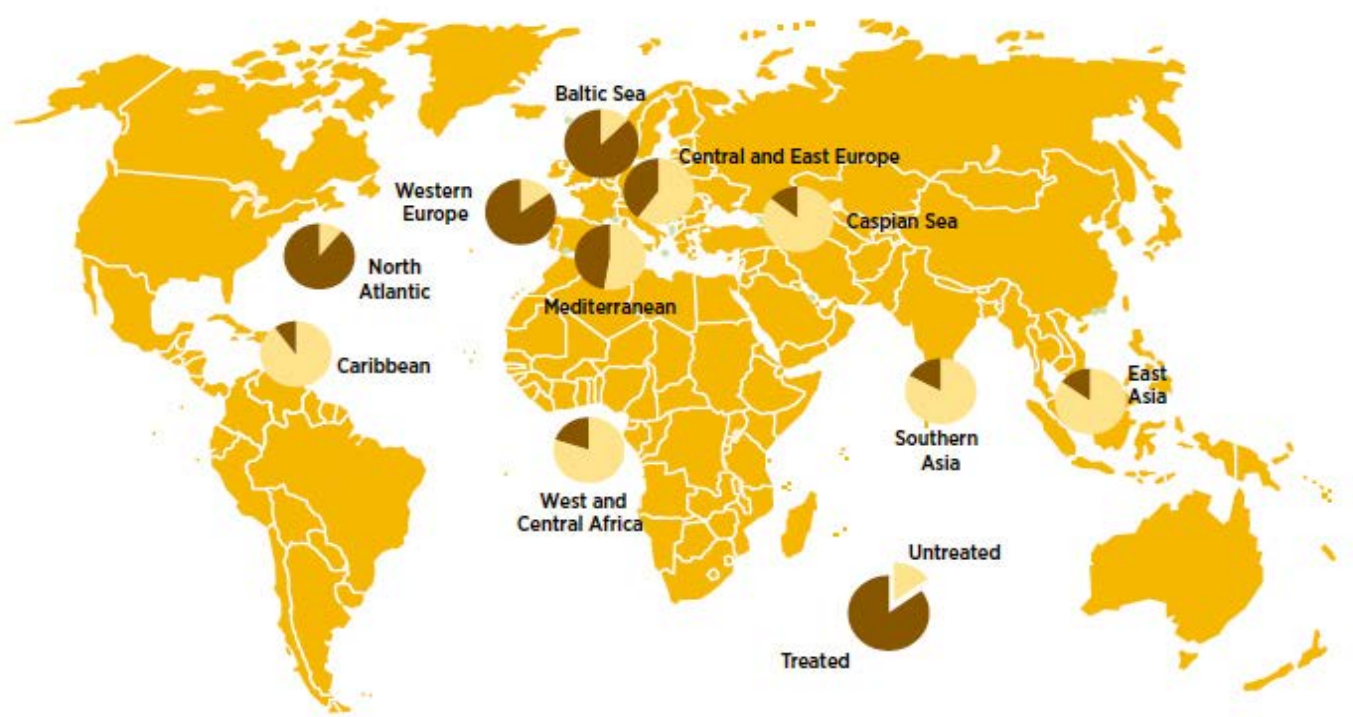

Figure 1.1. Ratio of treated to untreated wastewater discharged into water bodies. (Source: adaptation of UNESCO, 2012).

During the last decade, the occurrence of organic micropollutants in the environment has attracted great interest since a generalized concern arise about the possible undesirable effects of many of these pollutants in the environment and to living organisms (Cunningham et al., 2006; Kümmerer et al., 2009). The trace pollutants referred to as 'emerging organic contaminants' (EOCs) mainly comprise a group of man-made compounds such as pharmaceutical and personal care products (PPCPs), pesticides, plasticizers and antiseptics that are continuously discharged into the environment as a result of consumer activities, waste disposal, accidental releases and purposeful introduction (Daughton, 2004a).

One of the main sources of EOCs into the environment is the discharge of effluents from wastewater treatment plants (WWTPs), where their removal is usually incomplete (Heberer, 2002). Although a whole array of advanced treatment technologies have lately appeared aiming at the elimination of EOCs, such as ozonation, chemical advanced oxidation or UV radiation (Kim et al., 2009; Liu et al., 2009; Rosal et al., 2010) and have shown to enhance their elimination, the cost of these treatments is oftentimes too expensive and not justified under the current concept and standards of sanitation and 
wastewater treatment. Moreover, they could lead to the generation of transformation products being in some cases more persistent or toxic than the parental compound (Fatta-Kassinos et al., 2011).

To this regard, decentralized, extensive low-cost treatment technologies, such as constructed wetlands, emerge as a great alternative for wastewater treatment and reuse, which require almost no maintenance and energy consumption. Constructed wetlands (CWs) are natural wastewater treatment systems that emphasize the processes happening in natural wetlands in order to improve their treatment capacity (Kadlec and Wallace, 2009). They constitute an alternative costeffective technology to conventional WWTPs, in particular in the context of small communities with less than 2000 people equivalent (PE) (Puigagut et al., 2007). Apart from the removal of conventional wastewater pollutants (e.g. biochemical oxygen demand, total suspended solids, nitrogen, phosphorus, etc.) and heavy metals, CWs have proven to have a great potential for the removal of EOCs. The existing literature includes mostly studies on the occurrence and behavior of pharmaceuticals at horizontal flow (HF) wetlands at micro and meso-scale (Matamoros et al., 2008a; Ávila et al., 2010; Hijosa et al., 2010b; Dordio et al., 2010; Hijosa et al., 2011b; Zhang et al., 2011; Reyes-Contreras et al., 2012; Zhang et al., 2012b; Ávila et al., 2013a), as well as pilot-scale (Matamoros and Bayona, 2006; Matamoros et al., 2005). Moreover, several studies have been carried out in vertical flow (VF) systems (Matamoros et al., 2007; Matamoros et al., 2009a; Song et al., 2009) and others at full-scale tertiary treatment systems, which include the use of a free water surface (FWS) wetland (Matamoros et al., 2008b; Llorens et al., 2009; Hijosa et al., 2010a; Matamoros and Salvadó, 2012). A couple of other examples comprise the use of a CW after a previous treatment system like a conventional WWTP or an anaerobic digester (Reyes-Contreras et al., 2011; Verlicchi et al., 2013), and the use of a three-stage hybrid constructed wetland systems based on different wetland types (Ávila et al., 2014a, b). As an example, an aerial view of a surface constructed wetlands system, acting as a tertiary treatment unit after a conventional activatedsludge unit in Spain, which was evaluated by Matamoros et al. (2008b) can be observed in Figure 1.2.

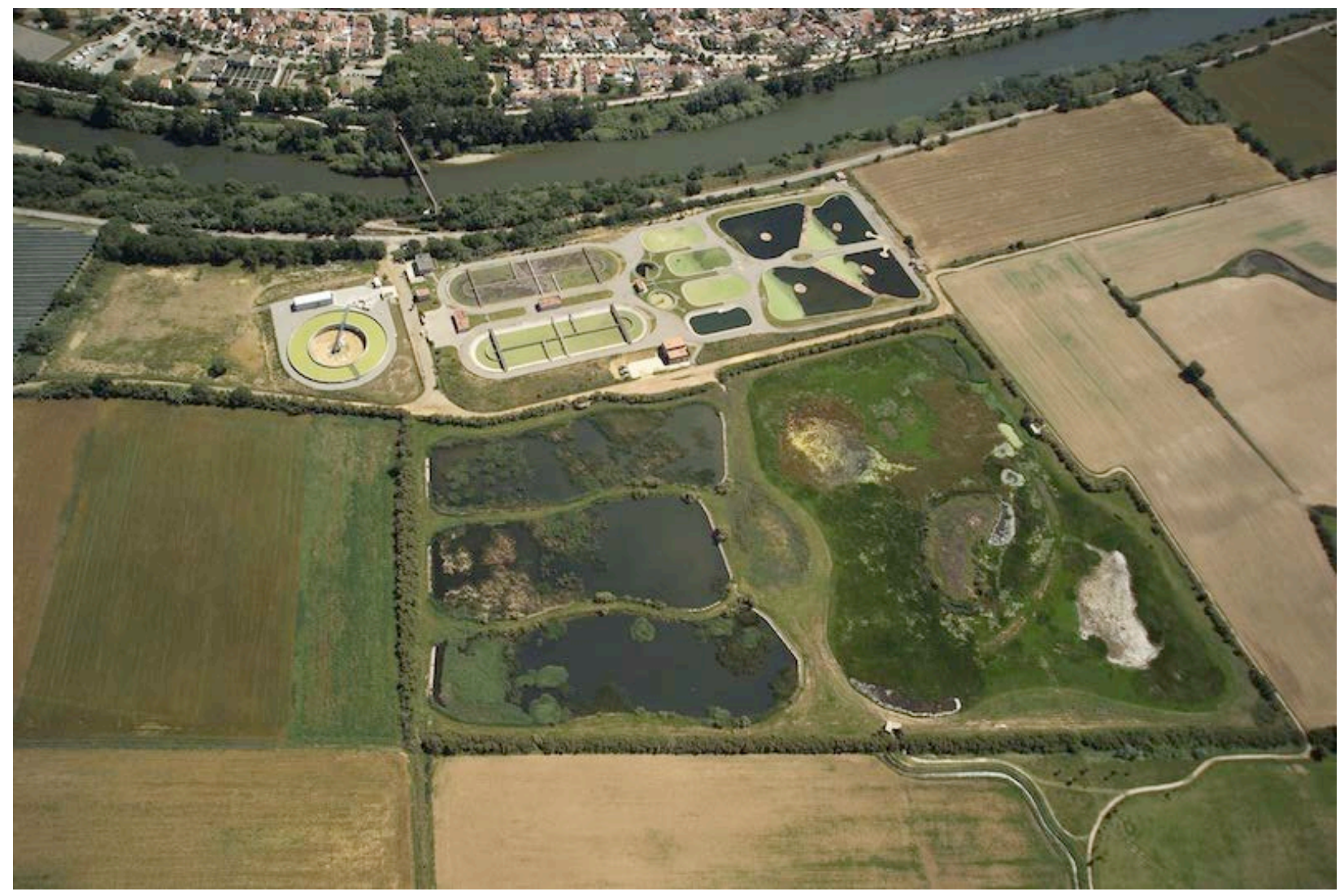

Figure 1.2. Aerial view of the activated sludge WWTP and tertiary treatment constructed wetland system at the Natural Park of Aiguamolls de l'Empordà, Girona, Spain (photo: Consorci Costa Brava).

With the purpose of providing further insight about the occurrence and possible undesirable effects of pharmaceuticals and personal care products in the environment, as well as the technologies which could avoid their release into the aquatic environment, in the current chapter we will describe the current knowledge on their source, fate and removal in conventional wastewater treatment plants and tertiary treatment units. 
Finally this chapter reviews the efficiency of constructed wetlands at removing pharmaceuticals and personal care products from domestic wastewater.

\subsection{Emerging organic contaminants}

Emerging organic contaminants (EOCs) are, in most cases, unregulated contaminants whose emissions have emerged as an environmental problem. They comprise a diverse collection of thousands of chemical substances, such as pharmaceuticals, personal care products (PCPs), pesticides, hormones, surfactants, flame-retardants, plasticizers, industrial additives and agents, as well as their transformation products (Farré et al., 2008). The steady increase in the manufacture and consumption of this type of compounds (Campbell, 2007), together with the development of new analytical techniques that have allowed their detection (González et al., 2007, Farré et al., 2012), and attracted the attention and concern of the scientific community around a decade ago (Halling-Sorensen et al., 1998). Since then, a number of authors have done extensive research about the occurrence, fate and ecotoxicological effects of these pollutants in the environment (Kolpin et al., 2002; Cunningham et al., 2006; Barceló and Petrović, 2007; Brooks et al., 2012).

Europe stands as a pioneer in this field and many programs/projects are carried out, which investigate the occurrence, fate and ecotoxicology of these pollutants in all the different compartments of the aquatic environment, as well as potential solutions concerning the elimination of these in wastewater. Some examples of finalized projects are:

- POSEIDON (2001-2004): Assessment of Technologies for the Removal of Pharmaceuticals and Personal Care Products in Sewage and Drinking Water Facilities to Improve Indirect Potable Water Reuse

- P-THREE (2002-2005): Removal of Persistent Polar Pollutants through Improved Treatment of Wastewater Effluents

- EMCO (2004-2007): Reduction of Environmental Risks, Posed by Emerging Contaminants, through Advanced Treatment of Municipal and Industrial Wastes

- ERAPharm (2004-2007): Environmental Risk Assessment of Pharmaceuticals

- KNAPPE (2007-2008): Knowledge and Need Assessment on Pharmaceutical Products in Environmental Waters

- PILLS (2009-2012): Pharmaceutical Input and Elimination from Local Sources

In September 2005 the NORMAN network (Network of reference laboratories for monitoring of emerging environmental pollutants) was created with the financial support of the European Commission, with the purpose of being a self-sustaining network of reference laboratories, research centers and related organizations around Europe for the monitoring and biomonitoring of EOCs. The aim is to enhance the exchange of information, to harmonize methodologies and to stimulate coordinated, interdisciplinary projects on problem-oriented research to address identified needs.

Likewise, the Environmental Protection Agency (EPA, USA) has also made great efforts to raise attention about the potential problems derived from the ubiquity of pharmaceuticals in the environment, not only asking scientist to increase the research on the field, but also calling the attention of authorities, health care providers, pharmaceutical companies and patients (Daughton and Ternes, 1999; Daughton, 2004b). The ultimate goal is to develop mitigation practices to tackle this environmental problem and to avoid the risk associated with these pollutants (Barceló, 2003).

However, though major strides have been made in the last years in increasing knowledge about the matter, one of the main conclusions at this point is that knowledge about emerging contaminants' fate and impact in the environment and living organisms is, however, fragmentary, and often dealing with only a part of the problematic, and therefore much remains to be understood (KNAPPE, 2008).

Out of the rich array of EOCs, the ones receiving the greatest attention up to date are the following: antibiotics, due to the increase in antibiotic resistance genes in aquatic microbiota and potentially human pathogens (Díaz-Cruz et al., 2003; Knapp et al., 2010; Patra et al., 2012; Rodríguez-Rojas et al., 2013); then, X-ray contrast media, which have shown high persistence in the environment; cytostatic drugs, which, being majorly used in the chemotherapy of oncological patients, 
are designed to prevent the growth and proliferation of cells, and thus are considered highly hazardous compounds due to their genotoxic properties (Zhang et al., 2013); and finally endocrine disrupting compounds (EDCs) such as estrogens, PCBs and organochlorine pesticides (e.g. DDT), among others, which have been found to induce disruption of the reproductive system, female and male reproductive health in humans and wildlife, sex ratio (in wild fish and mollusks), neurodevelopment in children and wildlife, as well as to cause hormone-related cancers, bone disorders, metabolic disorders, and even immune function, diseases and disorders in humans and wildlife (Bergman et al., 2013).

Daughton (2004b) conducted a great discussion about the universe of chemicals that occur in the environment, both known (regulated or not) and unknown, so as to put efforts in widening the understanding of the exposure and risk of chemicals in ecosystems and human health. A large portion of the chemicals occurring in analyzed water samples are not (or cannot be) identified, due to limitations in the repertoire of available analysis tools. Everyday, and for decades now, a whole array of new drugs are released into the environment with mechanisms of action never before encountered by biological systems, and only a very small percentage of commercially used contaminants are being investigated. Definitively, industrial and technological advances in respect to the production of chemicals poses substantial challenges to the evolution and design of regulatory practices.

The limited information on the occurrence, fate and effects of EOCs makes it difficult for authorities to regulate their disposal and limit their concentrations. Some groups of compounds have received regulation, such as pesticides and other priority pollutants (EC, 1976). Moreover, the European Commission is working on the preparation of a candidate list of 553 endocrine disrupting compounds (EDCs) so as to prioritize further detailed review of these. In this list, the industrial chemical bisphenol A (monomer of hard plastics and eposy resins) and the estrogenic steroid hormone $17 \alpha-$ ethinylestradiol are included, among others, together with many new pesticides and other industrial chemicals (EC, 2000b). This list is subjected to changes in response to developments in scientific knowledge or changes in patterns of chemical usage. On the other hand, in the USA the EPA holds a list of compounds called the Contaminant Candidate List (CCL), which comprises a list of contaminants that although are not subject to any drinking water regulation, are being monitored with the aim of possibly being included in future regulations. The last one includes several EDCs, and some flame-retardants (CCL3, 2008).

However, there are no laws, acts or regulations of any kind, which include guidelines for EOCs concentrations in WWTPs, drinking water facilities or the environment. The lack of regulations allows unlimited and widespread discharge of EOCs in the environment, which have unknown consequences for the environment and public health. Efforts should be harmonized and integrated between the different actors involved in EOCs' lifecycle, as well as researchers and public authorities, so as to obtain more productive outcomes and understanding of the problematic and to take action to limit their presence in the environment (Schwarzenbach et al., 2006; KNAPPE, 2008; Daughton, 2009).

\subsubsection{Pharmaceuticals and personal care products}

There is a large number of EOCs that are continuously released to the environment due to their wide use in society. A subclass underneath this class is pharmaceuticals and personal care products (PPCPs), which in turn comprise an extraordinarily diverse group of chemicals used in veterinary medicine, agricultural practice, human health and cosmetic care.

PPCPs include prescription and non-prescription medications, nutritional supplements, diagnostic agents, as well as other consumer products such as disinfectants, fragrances, sunscreen and cosmetics. Even though most of them are polar, have a short half-lifetime in water, and are found in trace concentrations, they are considered pseudo-persistent pollutants (Barceló and Petrović, 2007). This is because their universal, frequent usage by multitude of individual and animals causes a continuous discharge into the environment often times sourcing from either non-treated or insufficient wastewater treatment.

The molecular structures of PPCPs are typically large and complex, and differ a lot among substances, containing functional groups such as hydroxyl, carboxyl, ketone and amine. It is important to note that the classification of pharmaceuticals by their active substances within subgroups of pharmaceuticals does not imply that they follow a certain chemical behavior. Small changes in the chemical structure may have significant effects on solubility and polarity, and 
other properties, which will in turn determine their environmental distribution in air, water, sediments, soils and animals (Kümmerer, 2009).

One of the physico-chemical properties of organic compounds most applied in the field of environmental chemistry is the $n$-octanol water partition coefficient $\left(\mathrm{K}_{\mathrm{ow}}\right)$, which is defined as the ratio of the compound's concentration in a known volume of $n$-octanol to its concentration in a known volume of water at equilibrium and at constant temperature. $\mathrm{K}_{\mathrm{ow}}$ values are constant for a given compound and reflect the lipophilicity of a compound. Hence, the higher the $\mathrm{K}_{\mathrm{ow}}$ of a chemical, the higher its lipophilicity. $\mathrm{K}_{\mathrm{ow}}$ values are generally directly proportional to molecular weight.

$\mathrm{K}_{\mathrm{ow}}$ values can be measured in the laboratory with shake-flask systems, or can be estimated by models. $\mathrm{K}_{\mathrm{ow}}$ values have been measured for a wide variety of chemicals and range from about 0.001 to over 10,000,000. Since the range of $K_{\text {ow }}$ values encompass ten orders of magnitude, $\log \mathrm{K}_{\mathrm{ow}}$ values are used instead, and range -3 to 7 . A substance is usually considered lipophilic at $\log \mathrm{K}_{\mathrm{ow}}$ values ranging 3-4 to 6.5 ( $\left.\mathrm{K}_{\mathrm{ow}}>100\right)$ (Connell, 2005).

However, $\mathrm{K}_{\mathrm{ow}}$ assays are done adjusting the $\mathrm{pH}$ of the aqueous phase so that the predominant form of the compound is unionized. In this way, although some substances could be expected to be fairly lipophilic when having $\log \mathrm{K}_{\mathrm{ow}}$ values ranging 3-4, the occurrence of carboxylic groups or other polar groups in their structure are prone to be ionized and thus, increasing their hydrophilicity. Since many pharmaceuticals are ionizable at environmental $\mathrm{pH}$ conditions, $\log \mathrm{K}_{\mathrm{ow}}$ might not always be an appropriate predictor of the hydrophobicity of a compound. In particular, most non-steroidal antiinflammatory drugs (NSAIDs) are ionized at environmental $\mathrm{pH}$, and behave as highly polar compounds. Hence, for weak acids the hydrophobicity also depends on its $\mathrm{pK}_{\mathrm{a}}$ and the occurring $\mathrm{pH}$ of the media where they are contained (Eq. 1).

The ionization constant $\left(\mathrm{K}_{\mathrm{a}}\right)$ is a measure of (weak) acid strength as expressed by the concentration of ionized molecules divided by the concentration of unionized molecules. In this way, the lower the $\mathrm{pK}_{\mathrm{a}}$, the higher the $\mathrm{K}_{\mathrm{a}}$ and the stronger the acid.

where,

$$
\log \left[\mathrm{A}^{-}\right] /[\mathrm{AH}]=\mathrm{pH}-\mathrm{pKa} \quad \text { (Equation 1) }
$$

Hence, for a given $\mathrm{pK}_{\mathrm{a}}$ of a compound, the higher the $\mathrm{pH}$, the higher the ionization of the compound.

To this regard, the octanol-water distribution coefficient $\left(\mathrm{D}_{\mathrm{ow}}\right)$, which is defined as the ratio of the sum of all forms of the compound (ionized + unionized) in each of the two phases, constitutes a better descriptor for ionizable compounds. In this case the $\mathrm{pH}$ of the aqueous phase is buffered to a specific value such that the $\mathrm{pH}$ is not significantly perturbed by the introduction of the compound. The $\log \mathrm{D}_{\mathrm{ow}}$ is $\mathrm{pH}$ dependent, and hence one must specify the $\mathrm{pH}$ at which the parameter was measured. For unionizable compounds, $\log \mathrm{K}_{\mathrm{ow}}=\log \mathrm{D}_{\mathrm{ow}}$ at any $\mathrm{pH}$, however for many pharmaceuticals such as NSAIDs (e.g. ibuprofen, diclofenac), the molecule occurs mainly in its ionized form and thus holds a hydrophilic behavior at environmental $\mathrm{pHs}\left(\log \mathrm{D}_{\mathrm{ow}}=1.1\right.$ for both substances at $\left.\mathrm{pH}=8\right)$.

In the case of personal care products (PCPs), fragrances are generally semi-volatile organic compounds, fairly hydrophobic substances, which have been for many centuries used for multiple purposes (e.g. perfumes, deodorants, washing and cleaning agents, cosmetics). Typical concentrations of fragrances range from $0.3 \%$ in face creams to as much as 20\% in perfume extracts (Cadby et al., 2002). Most of the fragrances used nowadays are synthesized by industry, and nitro musks and polycyclic musks are the two main categories. The latter are the major musks used today, accounting for almost two-thirds of worldwide production, with an estimated worldwide production volume of $6000 \mathrm{t}$ year $^{-1}$ (Rimkus, 1999). Tonalide (AHTN) is one of the most widely used polycyclic musks around the world and is used in cosmetics and detergents. It is designed to be very lipophilic in order to sorb to organic materials such as the skin, and in consequence is poorly soluble in water, as indicated by its high octanol-water coefficient $\left(\log \mathrm{K}_{\mathrm{ow}}=5.9\right)$. Moreover, oxybenzone (OXY) is an organic ultraviolet filter used in sunscreen and other cosmetics. Another commonly found PCP is triclosan (TCS), an antibacterial and antifungal agent present in soaps, deodorants, toothpastes, shaving creams, and in a number of consumer products (MedlinePlus, 2010). PCPs differ from pharmaceuticals in that large amounts can be directly introduced in the environment, by direct release into recreational waters or volatilized into the air (e.g. musks). 


\subsubsection{Transformation products}

The compounds resulting from the structural change of pharmaceuticals within the human body are called metabolites. As with metabolism, when a substance is introduced to the environment or a treatment plant, it can undergo different structural changes by a variety of biotic (e.g. biodegradation, biotransformation) and non-biotic processes (e.g. phototransformation, hydrolysis) resulting in partial or complete transformation of the original compound. This results in changes in their physico-chemical properties, which in turn affects their behavior and toxicity. Although the transformation of parent compounds could be expected to reduce toxicity, in some cases transformation products could have higher persistence and/or more harmful effects than the parent substance. This has particularly been found during natural and technical photolytic processes and advanced oxidation processes (AOPs) (Kümmerer, 2009; Fatta-Kassinos et al., 2011; Benítez et al., 2013).

Little is known about the degradation pathways and products of most PPCPs in the environment, and less is known about their intermediates of degradation, which just started to be explored (Miao and Metcalfe, 2003; Farré et al., 2008). Gómez et al. (2012) just recently found transformation products of various PPCPs at the Henares River basin (central Spain) at concentrations much higher than those of their parent compounds. Various transformation products of ibuprofen and other pharmaceuticals were identified by Quintana et al. (2005) in municipal wastewater treated by a membrane bioreactor.

These findings highlight the importance of including degradation products in monitoring and research programs so as to have a better understanding of the behavior and potential toxicology of PPCPs in the environment. However, it is important to have in mind that given the universe of chemicals that are everyday released into the environment and, the difficulty and expense involved in their analysis, it would be impossible (if not infinite) to take them all into consideration for research programs or rutinary monitoring. Instead, well-balanced efforts must be put based on predicted risks associated to each specific contaminant in order to find a compromise solution.

\subsection{Sources and fate of pharmaceuticals and personal care products in the environment}

Contaminants enter the environment through multitude of sources, whose components are depicted in Fig. 1.3.

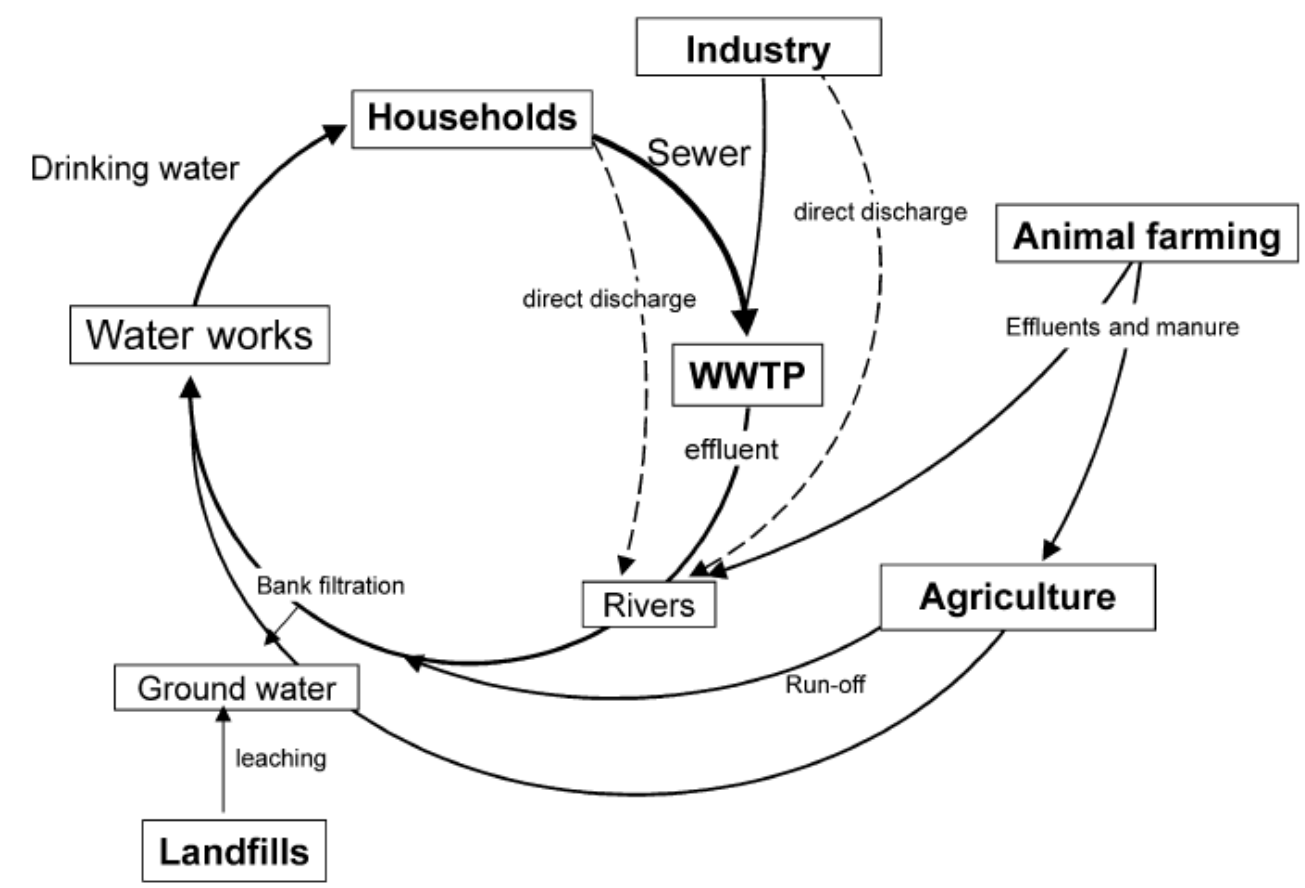

Figure 1.3. Sources and fate of contaminants in the (partially) closed water cycle with indirect potable re-use (from Petrović et al., 2003). 
Consumption of PPCPs is high worldwide. As an example of human consumption, it is worth noting how the consumption of non-steroidal anti-inflammatory drugs (NSAIDs) in Spain raised from 26.30 DHD (defined daily doses/1000 inhabitants·day) to 45.81 DHD from 1992 to 2006 (AEMPS, 2006). Out of the NSAIDs, one of the compounds attaining the greatest increase was ibuprofen, whose consumption increased from 0.29 DHD in 1992 up to 21.30 in 2006. The NSAID DCF (commonly known as voltaren) however showed rather stable values of consumption overtime, averaging 7 DHD. According with IMS Health data 942 tons of the anticonvulsant carbamazepine and 877 tons of DCF were sold in 2007 in 76 major countries, which are believed to account for $96 \%$ of the global pharmaceutical market. Antibiotic consumption did not fluctuate a lot during the last decade in Spain as it is shown in the report of the AEMPS (2009). Values ranged 0.1 DHD for most studied quinolones up to a maximum value of 6.6 DHD found for the peniciline amoxicilin. As it can be seen in the report by the OECD, most countries in the world have experimented a significant increase in consumption of pharmaceuticals in the last decade (OECD, 2013). To this regard, Daughton and Ruhoy (2013) have called to note the importance of prescribing the "lowest effective dose" of pharmaceuticals on patients as a strategy to diminish PPCP concentrations in the environment and eventually avoid potential adverse environmental impacts.

Once pharmaceuticals are ingested and a fraction metabolized, they are excreted and reach the urban sewer network up to the wastewater treatment plants. The current treatment processes applied for municipal wastewater treatment often fail to completely remove PPCPs, which leads to their subsequent release in the terrestrial and aquatic ecosystems through disposal and reuse applications.

On the other hand, the second major source of PPCPs in the environment after sewage effluent discharge is terrestrial run-off derived from the agrifood (and especially meat) industry. To have an idea of the levels of consumption of antibiotics on livestock farms, while human antibiotic use in the USA is maintained below 8 billion pounds per year, livestock farms have been increasing their use, constituting to date nearly four-fifths of the total amount of antibiotics used in the USA (FDA, 2011).

A significant source of concern for PPCPs in groundwater is the leaching from municipal landfills. Improper disposal of unused or expired drugs (either through the toilet or landfill) constitute another source of these contaminants in the environment. Depending on the physico-chemical characteristics of the organic contaminant (and their transformation products) and the characteristics of the soil, PPCPs can either reach groundwater and pollute aquifers or remain retained within the soil and eventually accumulate, thus affecting the ecosystem and human beings through the food-web. As a matter of fact, PPCPs have been detected at trace concentrations in the freshwater environment for decades (HallingSorensen et al., 1998; Kolpin et al., 2002; Loos et al., 2009, 2010; Jurado et al., 2012). As a particular example, Kim et al. (2007) documented the frequent detection of many pharmaceuticals, hormones, antibiotics, as well as flameretardants in surface waters in South Korea. Various endocrine disrupting compounds (EDCs), as well as associated toxicological effects over caged male fathead minnows, were found in $90 \%$ of sediment and water samples of 11 studied lakes across Minnesota, USA (Writer et al., 2010). Stackelberg et al. (2004) found pharmaceuticals compounds and other organic wastewater contaminants in a conventional drinking-water-treatment plant before and after treatment. Pharmaceuticals were also found at the $\mathrm{ng} \mathrm{L}^{-1}$ level in the tap water of Berlin (Heberer, 2002). The authors attribute this phenomenon to be characteristic of conurbations like Berlin, with high municipal wastewater discharges and low surface water flows, when groundwater recharge is used in drinking water production.

Some other scattered examples, which show the ubiquity of the occurrence of PPCPs in various compartments of the aquatic environment around the world, are displayed in Table 1.1.

Table 1.1. Minimum, maximum and average concentrations (in $n g \mathrm{~L}^{-1}$ ) of various PPCPs in natural water bodies around the globe.

\begin{tabular}{lccccc}
\hline & Min & Max & Avg & Sample source & Reference \\
\hline Diclofenac & 10 & 50 & 29 & River Elbe and at the mouth of its & Wiegel et al. (2004) \\
Ibuprofen & $<20$ & 70 & 35 & tributaries (Germany) & \\
Acetaminophen & $<5$ & 65 & 16 & & \\
Bisphenol A & 16 & 100 & 40 & & Kim et al. (2007)
\end{tabular}




\begin{tabular}{|c|c|c|c|c|c|}
\hline Acetaminophen & 4 & 73 & 33 & \multirow[t]{3}{*}{ Korea) } & \\
\hline Diclofenac & 1 & 6.8 & 3.0 & & \\
\hline Oxybenzone & 1 & 3 & 2 & & \\
\hline Acetaminophen & $<\mathrm{LOD}$ & 712 & - & Ebro River basin (Spain) & López-Serna et al. (2012) \\
\hline Triclosan & $<\mathrm{LOD}$ & 8 & n.a. & Surface waters of Greenwich Bay (USA) & Katz et al. (2013) \\
\hline Acetaminophen & 2 & 17 & 5 & \multirow{2}{*}{$\begin{array}{l}\text { Near-shore habitats of Lake Michigan - } \\
\text { river discharges into the lake from } \\
\text { predominantly urban watersheds (USA) }\end{array}$} & \multirow[t]{2}{*}{ Ferguson et al. (2013) } \\
\hline Ibuprofen & 2 & 84 & 8 & & \\
\hline Carbamazepine & 2 & 118 & 40 & \multirow{3}{*}{$\begin{array}{l}\text { Aquifers at the delta area of the Llobregat } \\
\text { River (NE Spain) }\end{array}$} & \multirow[t]{3}{*}{ Teijón et al. (2010) } \\
\hline Ibuprofen & $<$ LOD & 185 & 185 & & \\
\hline Diclofenac & 35 & 477 & 256 & & \\
\hline Acetaminophen & - & 1890 & 180 & $\begin{array}{l}\text { Groundwater used for drinking-water } \\
\text { supply in California (USA) }\end{array}$ & Fram and Belitz (2011) \\
\hline Diclofenac & $<\mathrm{LOD}$ & 1.2 & 0.2 & \multirow{5}{*}{$\begin{array}{l}\text { Urban groundwater in the district of Poble } \\
\text { Sec, Barcelona (Spain) }\end{array}$} & \multirow[t]{5}{*}{ López-Serna et al. (2013) } \\
\hline Ibuprofen & $<\mathrm{LOD}$ & 2 & 0.2 & & \\
\hline Acetaminophen & $<\mathrm{LOD}$ & $<\mathrm{LOD}$ & $<\mathrm{LOD}$ & & \\
\hline Erythromycin & $<\mathrm{LOD}$ & $<\mathrm{LOD}$ & $<\mathrm{LOD}$ & & \\
\hline Enrofloxacin & 12 & 264 & 75 & & \\
\hline Ibuprofen & $<\mathrm{LOD}$ & 200 & - & \multirow[t]{3}{*}{ Berlin groundwater wells (Germany) } & \multirow[t]{3}{*}{ Heberer (2002) } \\
\hline Diclofenac & $<\mathrm{LOD}$ & 380 & - & & \\
\hline Clofibric acid & $<\mathrm{LOD}$ & 7300 & - & & \\
\hline
\end{tabular}

Concentrations of PPCPs in surface waters (primarily due to their incomplete elimination in WWTPs) as well as groundwater (due to filtration through the soil) are in the range of $n g \mathrm{~L}^{-1}$ to $\mu \mathrm{g} \mathrm{L}^{-1}$. The different pathways that PPCPs can undertake from resource up to drinking water level are explained in detail in the study by Halling-Sørensen et al. (1998). In general, the polar nature and low volatility of PPCPs prevents their escape from the aquatic realm, being primarily distributed through aqueous transport and food chain dispersal (Daughton and Ternes, 1999). Although the half-life in aquatic ecosystem for most PPCPs is relatively low (Yamamoto et al., 2009), some substances are fairly recalcitrant and may accumulate in soil, reaching concentrations of $\mathrm{g} \mathrm{kg}^{-1}$. As an example, clofibric acid (a compound used for reducing cholesterol levels in blood) has been found to have a half-life of 21 years in soil (Hernando et al., 2006). In relation to this, the application of sewage sludge could eventually contribute to soil, surface and groundwater contamination, either by accumulation of these contaminants in soil in the long term, or by possible leaching and migration of contaminants through the soil zone (Chen et al., 2011; Stuart et al., 2012). Another major pathway of groundwater contamination is due to groundwater-surface water interaction through infiltration from losing reaches of rivers, especially near industrial premises and sewage works (Stuart et al., 2012). The contamination of the groundwater could pose serious challenges to safety regarding drinking water supply. A recent study by the GAO (2011) showed that most drinking water samples grabbed in USA were contaminated by pharmaceuticals, mostly estrogen-based hormones and antibiotics.

Moreover, there is a clear need to include irrigation as an additional exposure route for PPCPs in terrestrial ecosystems, so as to assess the potential risks derived. Driven by the imposing water scarcity, irrigation through water reclamation is being widely implemented in Europe for multiple purposes, mainly agriculture, due to the advantages related to nutrient recovery, socio-economic implications. The practice of wastewater reuse without proper management poses potential risks to human health and the environment due to the potential occurrence of pathogens and chemical pollutants (Muñoz et al., 2009; Fatta-Kasinos et al., 2011). 


\subsection{Toxicity and evaluation of risks associated to pharmaceuticals and personal care products}

The ubiquity of PPCPs in the environment has created a great concern among scientists due to the possible toxicological effects that these substances may pose on ecosystems and public health. In the last years numerous studies are evaluating the possible toxicological effects related to the occurrence of PPCPs and other emerging organic contaminants, mainly on aquatic organisms (Fent et al., 2006), as well as the management of risk (Enick and Moore, 2007) with the purpose of giving support to decision taking by stakeholders and eventually policy-making.

Although occurring concentrations of PPCPs in the environment are oftentimes very low (ranging $n g \mathrm{~L}^{-1}$ to $\mu \mathrm{L} \mathrm{L}^{-1}$ ) and may not seem to pose an appreciable risk to human health, these are continuously released to the environment, constituting so-called "pseudo-persistent” contaminants. In many cases the possible consequences of their occurrence in the environment are not well understood, but in others the effects seems evident and alarming. As an example, the reduction of $90 \%$ of the population of vultures in India, Pakistan and Nepal since the 1990's is related to the use of the anti-inflammatory drug diclofenac on cattle in these countries, and therefore its use as a veterinary drug was banned in 2005 in India (Oaks et al., 2004; Balmford, 2013).

What is more, musk fragrances are found to be ubiquitous, persistent, bioaccumulative pollutants in aquatic organisms that are sometimes highly toxic (Daughton and Ternes, 1999; Luckenbach et al., 2004; Zhang et al., 2013). Amino musk transformation products are toxicologically significant. Polycyclic musks fragrances have been found to accumulate in several aquatic organisms, such as fish and mussels, but also in high trophic level aquatic organisms and human breast milk (Kannan et al., 2005; Yin et al., 2012).

It is important to note that pharmaceuticals are designed to be biologically active, by modulating endocrine and immune systems and cellular signal transduction, in order to serve their therapeutic purposes. This in consequence will potentially affect the physiological and biochemical functions of biological systems and ecosystems. Moreover, some of them are estrogen hormones (such as ethynilestradiol), which belong to the category of endocrine disrupting coumpounds (EDCs), showing toxicity at $\mathrm{ng} \mathrm{L}^{-1}$ levels (Larsson et al., 1999; Ingerslev et al., 2003). However, PPCPs are quite diverse among them and therefore they may have very different effects over ecosystems (Halling-Sorensen et al., 1998). Although PPCPs have received less scrutiny than pesticides (many are EDCs of concern), these differ from the latter in that the disposal of PPCPs is widespread, long-term and in lower doses. Thus aquatic organisms receive a more chronic exposure.

Although little is known about the occurrence and effects of pharmaceuticals in the environment, more data exist for antibiotics than for any other therapeutic class. This is a result of their extensive use in human therapy and animal husbandry, as well as plant agriculture and aquaculture. It has become clear that the intense use and misuse of antibiotics has increased and spread the occurrence of highly resistant pathogenic bacteria. There is real concern about the effects on aquatic microbiota and consequent alteration of the structure of the microbial community, as well as on the development of resistance in potential human pathogens. Although occurring bacteria in freshwater sources are commonly non pathogenic, there could be exchange of genetic material between pathogenic and non-pathogenic bacteria, conferring them increased antibiotic resistance (Witte, 1998; Barbosa and Levy, 2000; Cabello, 2006; Schlüter et al., 2007; Kelly et al., 2009; Zhang et al., 2009; Middleton and Salierno, 2013).

Research efforts aiming at elucidating the potential toxicological significance of PPCPs in ecosystems and eventually in public health requires documentation of contaminant uptake, modes of action and biological endpoints, as well as exposure. Most of the published literature is based on acute effects on aquatic organisms, and in hazard and risk assessments. Assessment factors are applied to the acute effects data for extrapolation to chronic (long-term) effects. This approach is oftentimes non realistic, given that the ratio between acute and chronic toxicity shows to differ depending on the PPCP (Cunningham et al., 2006; Fent et al., 2006). In general, PPCPs do not show high acute toxicity, but chronic toxicity and potential subtle effects are marginally known.

As an example, Cleuvers (2003) found how the non-steroidal antiinflammatory drugs (NSAIDs) ibuprofen (IB) and diclofenac (DCF), and the anticonvulsant carbamazepine (CBZ) were toxic for algae, and discuss that although acute effects of single substances in the aquatic environment are very unlikely due to the small concentrations, a combination effect of several compounds and/or their transformation products can occur. Brausch and Rand (2011) evaluated acute and chronic toxicity data available for personal care products, including the antiseptic triclosan (TCS) and the musk fragrance tonalide (AHTN). Only TCS and Triclocarban presented any hazard. Moreover, Breitholtz et al. (2012) 
assessed the ecotoxicity of various micropollutants on macroalgae and crustaceans in a free water surface wetland in Sweden and reported a good quality of the effluent water, comparable to that treated under advanced tertiary treatment processes.

Conversely, Fent et al. (2006) found how a few substances such as DCF, was the compound with the highest acute toxicity within the class of NSAIDs, and average concentrations found at the effluent of conventional WWTPs were in the range of those being toxic for fish. What is more, Lai et al. (2002), using a food-web model found that natural and synthetic estrogens, such as the hormone ethynilestradiol (EE2), could be bioaccumulated in fish in river systems, although to a lesser extent than other EDCs such as DDT (Lai et al., 2002). Likewise, AHTN and other fragrances, which are made hydrophobic so as to adsorb to tissue might accumulate in aquatic biota (Rimkus, 1999).

Although acute toxicity in the aquatic systems due to the occurrence of PPCPs is unlikely to occur, there is a lack of chronic toxicity data and effects from long-term, low-level environmental exposures should be further addressed, so as to have a better understanding of the environmental risk of these compounds. What is more, since pharmaceuticals are not present alone in the environment, but as multi-component mixtures, an accurate prediction of the chronic mixture toxicity is indispensable for an environmental risk assessment. Significant synergistic toxic effects may occur through additive exposures; therefore they should not be handled in isolation. The effects and interaction of a cocktail of commonly used pharmaceuticals, including CBZ, IB and the antibiotic sulfamethoxazole were studied using in vitro tests on human and zebrafish cells by Pomati et al. (2008), and they found that the mixture of drugs at ng $\mathrm{L}^{-1}$ can inhibit cell proliferation on aquatic life. However, the research in this new field of ecotoxicology is just starting and much remains to be learned (Kümmerer, 2009; Stuart et al., 2012).

Another issue of very recent concern is the inhibition of multixenobiotic resistance (MXR) in aquatic organisms, which has especially been found in environmental samples from polluted locations. This mechanism is used as a "first line of defense" against endogenous and exogenous potentially toxic xenobiotics, which are expelled out of the cell by various transmembrane transport proteins. It is still unclear whether the so-called MXR inhibitors or chemosensitizers (Smital and Kurelec, 1998) are natural or man-made substances. It is also unknown whether these are constituted by a few powerful MXR inhibitors, or if the inhibition is caused by the mere presence of a large number of chemicals in polluted water. It is also discussed whether these substances could play key roles in potentiating the effects of other xenobiotics (Daughton and Ternes, 1999). Research on this topic has also just been initiated, such as the study of the inhibition of MXR by musk fragrances (Luckenbach et al., 2004) and still multiple aspects need to be addressed on this topic (Smital et al., 2004).

Even though ecological effects caused by PPCPs may not be manifest, it does not mean that they do not exist. Potential subtle effects of these substances over time may occur (Daughton and Ternes, 1999). In order to have a better understanding of mechanisms of action of these contaminants in the environment, the target- or biomolecule-oriented, or mode-of-action-based investigation activities are preferred over traditional standard ecotoxicological assays. In general, assessing the impact of PPCPs in aquatic systems remains a major challenge, requiring improved analytical and modeling tools, the development of methods to classify existing and new chemicals on the basis of their potential to harm humans and ecosystems, as well as the development of attenuation technologies and other strategies which minimize their introduction into the environment (Schwarzenbach et al., 2006).

\subsection{Occurrence and fate of pharmaceuticals and personal care products in conventional wastewater treatment plants}

The occurrence and fate of PPCPs have been extensively assessed in many conventional wastewater treatment technologies, such as activated sludge systems, which are oftentimes unable to degrade them, and thus constitute their major source point into the environment. The activated sludge process is the most common type of secondary treatment used in municipal wastewater treatment plants worldwide. It consists of a two-stage suspended growth biological treatment process designed to majorly remove organic matter. The first stage is comprised by an aerated reactor in which organic matter is eliminated by a mixed microbial population, while the second stage consists of a settling tank or clarifier that separates solids (activated sludge) from water. A portion of the activated sludge is wasted while the rest is returned back to the reactor. While hydraulic retention time (HRT) of the water is of about 8 hours, for conventional activated sludge, the average solids retention time is 5 to 10 days. Conventional WWTPs are an intensive wastewater 
treatment technology. They are able to treat great amounts of water, occupying a relatively small surface area (Tchobanoglous and Burton, 1991).

A compilation of results of various studies including influent and effluent concentration of PPCPs at conventional WWTPs based on activated sludge is displayed in Table 1.2.

Table 1.2. Minimum, maximum and (average) concentrations of various pharmaceuticals and personal care products (in ng $\mathrm{L}^{-1}$ ) and percentage of detection in influent and effluents of various conventional wastewater treatment plants around the world.

\begin{tabular}{|c|c|c|c|c|c|c|}
\hline Compound & WWTPs influent & \% detect. & WWTP effluent & \% detect. & Country & Ref. \\
\hline \multirow[t]{7}{*}{ Ibuprofen } & 1200-2679 (2021) & n.a. & $<$ LOD-2400 (489) & n.a. & Austria & 1 \\
\hline & 968-2986 (1681) & 100 & $131-424(263)$ & 100 & UK & 2 \\
\hline & $2800-25400(12500)$ & n.a. & $500-2600(1500)$ & n.a. & Greece & 3 \\
\hline & Max: 16500 (8450) & n.a. & Max: 773 (384) & n.a. & Canada & 4 \\
\hline & $170-83500(14600)$ & 97 & $2-24600(1960)$ & 93 & n.a. & 5 \\
\hline & $3730-353000(69700)$ & n.a. & $<$ LOD-26500 (4130) & n.a. & Spain & 6 \\
\hline & (1900) & n.a. & $(250)$ & n.a. & USA & 7 \\
\hline \multirow[t]{6}{*}{ Diclofenac } & $905-4114$ (2572) & n.a. & $780-1680$ (1366) & n.a. & Austria & 1 \\
\hline & $57-1161(260)$ & 100 & 6-496 (179) & 100 & UK & 2 \\
\hline & $<$ LOD-3900 (2000) & n.a. & <LOD-2600 (1300) & n.a. & Greece & 3 \\
\hline & Max:1010 (204) & n.a. & Max: 748 (194) & n.a. & Canada & 4 \\
\hline & $105-4110(1340)$ & 81 & $35-1950(680)$ & 85 & n.a. & 5 \\
\hline & $<\mathrm{LOD}$ & 0 & $<$ LOD & 0 & Spain & 6 \\
\hline \multirow[t]{5}{*}{ Acetaminophen } & $68107-482687$ (211380) & 100 & $1826-24525$ (11733) & 100 & UK & 2 \\
\hline & 108383-246641 (178116) & 100 & $>80-1575(353)$ & 86 & UK & 2 \\
\hline & $4700-52500(20600)$ & n.a. & $500-1700(900)$ & n.a. & Greece & 3 \\
\hline & 1571-37458 (23202) & n.a. & $<\mathrm{LOQ}$ & n.a. & Spain & 8 \\
\hline & $(960)$ & n.a. & $<\mathrm{LOD}$ & n.a. & USA & 7 \\
\hline \multirow[t]{3}{*}{ Tonalide } & $210-1106(760)$ & n.a. & $144-170(158)$ & n.a. & Austria & 1 \\
\hline & Max: 2000 (804) & n.a. & Max: 600 (274) & n.a. & Canada & 4 \\
\hline & $210-1690(990)$ & 100 & $144-200(162)$ & 100 & n.a. & 5 \\
\hline Oxybenzone & n.a. & n.a. & $1-30(11)$ & 71 & South Korea & 9 \\
\hline \multirow[t]{5}{*}{ Triclosan } & $33-463$ (228) & 100 & $13-82(57)$ & 100 & UK & 2 \\
\hline & $<$ LOD-1000 (800) & n.a. & $<\mathrm{LOD}$ & n.a. & Greece & 3 \\
\hline & 4010 (1930) & n.a. & Max: 324 (108) & n.a. & Canada & 4 \\
\hline & $1520-4430$ & n.a. & $(810)$ & n.a. & USA & 10 \\
\hline & $<$ LOQ-2417 (860) & n.a. & <LOQ-512 (219) & n.a. & Spain & 8 \\
\hline \multirow[t]{3}{*}{ Ethynilestradiol } & $0.4-70(4.2)$ & 91 & $0.2-5(0.9)$ & 59 & n.a. & 5 \\
\hline & $<$ LOD & 0 & $<\mathrm{LOD}$ & 0 & Sweden & 11 \\
\hline & n.a. & n.a. & 1.3 & 14 & South Korea & 9 \\
\hline
\end{tabular}

1. Clara et al. (2005), 2. Kasprzyk-Hordern et al. (2009), 3. Kosma et al. (2010), 4. Lishman et al. (2006), 5. Miège et al. (2009), 6. Santos et al. (2009), 7. Yu et al. (2006), 8. Rosal et al. (2010), 9. Kim et al. (2007), 10. Katz et al. (2013), 11. Zorita et al. (2009); n.a.: not available.

Non-steroidal antiinflammatory drugs (NSAIDs) take part of a therapeutical group widely used nowadays, and consequently acetaminophen and ibuprofen are the ones being found at higher concentration levels in raw wastewater. In the lower concentration level of PPCPs in the environment have been reported the detection of steroid hormones, generally at low ng L ${ }^{-1}$ and oftentimes below detection limits (Daughton and Ternes, 1999; Carballa et al., 2004). 
However, it should be noted that in spite of the low concentrations, estrogens could induce serious chronic effects, such as endocrine disruption (Ingerslev et al., 2003). The occurrence of antibiotics in WWTPs has also been reported in various studies (Yang and Carlson, 2004).

Activated sludge WWTPs are not specifically designed to eliminate PPCPs and thus removal rates are very variable and compound-dependent. A recent report by the EPA includes a review of recent literature on wastewater treatment technologies and their ability to remove 16 emerging organic contaminants, including many PPCPs. Average removal efficiencies were calculated from a collection of as many as 41 full-scale WWTPs based on activated sludge, and removal rates for various PPCPs are displayed in Table 1.3. Note that the treatment systems used to obtain the presented data on the table did not include activated sludge systems that reported design modifications from the conventional activated sludge WWTPs (e.g. those that aim to remove nutrients). Although there are many variations of this process, further division of activated sludge categories was impractical (EPA, 2010).

Table 1.3. Minimum, maximum and average removal efficiencies of various PPCPs at full-scale activated sludge WWTPs treating municipal wastewater (adapted from: EPA, 2010).

\begin{tabular}{lcccc}
\hline \multicolumn{1}{c}{ Compound } & \multicolumn{3}{c}{ Removal efficiency (\%) } \\
\cline { 2 - 5 } Ibuprofen & Min & Max & Avg & \# of WWTPs used to calculate removal \\
Acetaminophen & 43 & 100 & 90 & 32 \\
Diclofenac & $>90$ & 100 & 97 & 4 \\
Tonalide & 7 & $>99$ & 44 & 23 \\
Oxybenzone & 13 & 97 & 67 & 20 \\
Triclosan & $>8$ & $>96$ & 76 & 6 \\
Ethynilestradiol & $>67$ & 100 & 89 & 22 \\
\hline
\end{tabular}

Treatment performance was found to vary among the conventional WWTPs under study, majorly as a function of the characteristics of inflowing wastewater. Average removal efficiencies were very variable and compound-dependent.

PPCPs may be removed from wastewater during activated sludge treatment by mechanisms of biodegradation and/or adsorption to the particulate matter. Some compounds undergo rapid biodegradation (e.g. acetaminophen) in conventional WWTPs (Yu et al., 2006; Miège et al., 2009; Kosma et al., 2010; Rosal et al., 2010). Likewise, ibuprofen and triclosan are consistently removed in most treatment plants (Clara et al., 2005; Lishman et al., 2006). However, some compounds exhibit variable removal, (e.g. diclofenac), while others, such as carbamazepine, have shown to be very recalcitrant (Kosma et al., 2010). In fact, in some occasions higher concentrations have been found in the effluent than in the influent, which is attributed to desorption and/or deconjugation processes (Kasprzyk-Hordern et al., 2009; Zorita et al., 2009). The more hydrophobic substances may attach to suspended solids or activated sludge. To this respect, Carballa et al. (2005) found how compounds with high sorption properties such as tonalide and diclofenac were significantly removed during coagulation-flocculation assays encompassing different doses and types of coagulants at different temperatures, whereas hydrophilic compounds (e.g. ibuprofen and carbamazepine) were not affected. Conversely, Jelić et al. (2011) found no accumulation of diclofenac in sludge samples from three conventional WWTPs.

Treated effluent of WWTPs can either be disposed in surface waters or be reused for multiple applications. Additionally, the waste sludge, after its drying and treatment, could be applied to the land as fertilizers. In this way, remaining concentrations of PPCPs may transfer to soil and surface waters. 


\subsection{Removal of pharmaceuticals and personal care products through tertiary and advanced treatment technologies}

Since conventional activated-sludge WWTPs have shown to be unable to completely eliminate PPCPs, as well as other specific and priority substances included in the Water Framework Directive (EC, 2000a), a number of advanced (or tertiary) treatment technologies, which can provide further removal of these substances are being explored and developed lately in this sense. Already, a whole array of oftentimes fairly standardized unit processes is available so as to remove PPCPs by transformation or removal by physical and chemical methods, including adsorption or filtration. These include activated carbon (Ternes et al., 2002; Snyder et al., 2007), ozonation (Rosal et al., 2010), photo-Fenton (Rodríguez-Gil et al., 2010), UV radiation (Kim et al., 2009), ultrasonic irradiation (Naddeo et al., 2009), chemical AOPs (involving hydroxyl radicals), which generally use a combination of oxidization agents (e.g. $\mathrm{H}_{2} \mathrm{O}_{2}, \mathrm{O}_{3}$, $\mathrm{TiO}_{2}$, etc.), irradiation (UV or ultrasound) and catalysts (Klavarioti et al., 2009; Liu et al., 2009), chlorine dioxide oxidation (Huber et al., 2005), membrane technologies (Yoon et al., 2006; Snyder et al., 2007), and membrane bioreactors (Kimura et al., 2005; Quintana et al., 2005; Shariati et al., 2010). As an example the anti-inflammatory drug diclofenac has consistently shown to be well photodegraded under UV treatment (Andreozzi et al., 2003; Zhang et al., 2008; Kim et al., 2009). This substance also gets well mineralized under ozonation (Rosal et al., 2010) and chlorine disinfection (Kosma et al., 2010).

Average removal efficiencies of various PPCPs achieved under different tertiary treatment technologies are displayed in Table 1.4 (EPA, 2010).

Table 1.4. Min, Max and average removal efficiencies of various pharmaceuticals and personal care products under different advanced treatment technologies for municipal wastewater treatment at full-scale (EPA, 2010).

\begin{tabular}{|c|c|c|c|c|c|}
\hline Compound & Technology & Min & Max & Avg (\%) & $\begin{array}{c}\text { \# systems used to calculate } \\
\text { removal }\end{array}$ \\
\hline \multirow[t]{4}{*}{ Ibuprofen } & Chlorine disinfection & $>43$ & 100 & 78 & 5 \\
\hline & Ozonation & $>90$ & 100 & 95 & 2 \\
\hline & Reverse Osmosis & - & - & 72 & 1 \\
\hline & UV disinfection & $>81$ & 100 & 90 & 6 \\
\hline \multirow[t]{3}{*}{ Acetaminophen } & Chlorine disinfection & $>90$ & $>99$ & 95 & 2 \\
\hline & Reverse Osmosis & - & - & 90 & 1 \\
\hline & UV disinfection & - & - & 90 & 1 \\
\hline \multirow[t]{3}{*}{ Diclofenac } & Chlorine disinfection & $>18$ & $>90$ & 66 & 3 \\
\hline & Reverse Osmosis & - & - & 90 & 1 \\
\hline & UV disinfection & $>86$ & $>91$ & 89 & 3 \\
\hline \multirow[t]{2}{*}{ Tonalide } & Chlorine disinfection & 64 & 93 & 79 & 2 \\
\hline & UV disinfection & - & - & 52 & 1 \\
\hline \multirow[t]{3}{*}{ Oxybenzone } & Chlorine disinfection & $>8$ & $>95$ & 51 & 2 \\
\hline & Reverse osmosis & - & - & 95 & 1 \\
\hline & UV disinfection & $>89$ & $>96$ & 92 & 3 \\
\hline \multirow[t]{4}{*}{ Triclosan } & Chlorine disinfection & $>67$ & $>99$ & 83 & 4 \\
\hline & Ozonation & 99 & 100 & 99 & 2 \\
\hline & Reverse Osmosis & - & - & 67 & 1 \\
\hline & UV disinfection & $>71$ & $>99$ & 90 & 5 \\
\hline Ethynilestradiol & Chlorine disinfection & 1 & 72 & 42 & 4 \\
\hline
\end{tabular}

Although conventional tertiary or advanced treatment technologies have shown to enhance the elimination of these contaminants, they are very unlikely to be implemented in the context of wastewater treatment of small communities, even if the technology is improved, due to energy and economic constrains. To this regard, decentralized, extensive low- 
cost treatment technologies, such as constructed wetlands, emerge as a great alternative for wastewater treatment and reuse, which require almost no maintenance and energy consumption. Their successful implementation at full-scale has shown their capacity to degrade all kind of contaminants, from conventional parameters to heavy metals or pathogens. Just in recent years their potential on the removal of PPCPs is being explored. The characteristics, advantages and disadvantages and performance of constructed wetlands in the treatment of municipal wastewater are shown in the following section. 


\section{Constructed wetlands: a decentralized wastewater treatment ecotechnology}

Constructed wetlands (CWs) are natural wastewater treatment systems that consist of a properly designed shallow basin, which contains a substrate that is planted with aquatic vegetation. Other components such as microorganisms and aquatic invertebrates develop naturally. These systems are constructed to mimic the microbiological, biological, physical and chemical processes that occur in a natural wetland but in a more controlled environment to treat wastewater (Kadlec and Wallace, 2009).

These natural treatment systems constitute a cost-effective and technically feasible approach for the treatment of wastewater for several reasons:

- Can be less expensive to build than other treatment options.

- Low operational and maintenance (O\&M) expenses (energy and supplies). Easy to maintain (do not require highly qualified staff).

- $\quad$ Able to tolerate fluctuations in flow and load.

- Promote biodiversity. As an example, restored wetlands are becoming common in agricultural landscapes of northern Europe so as to increase nutrient retention as well as increasing species diversity (Thiere et al., 2009; Matamoros et al., 2012a).

- Can be easily integrated into the natural and rural landscape, and provide aesthetic, commercial and habitat value (Llorens et al., 2009).

- Possible commercial revenue from flower harvesting and/or aquaculture (Jana, 1998).

However, they have some limitations:

- Generally high land area requirement: they may be more economical than other technologies, but only if land is available and affordable. While activated sludge technology requires approximately $0.06 \mathrm{~m}^{2} / \mathrm{PE}$ (Cooper, 2005), vertical subsurface, horizontal subsurface and free water surface CWs require 2, 5 and $8 \mathrm{~m}^{2} / \mathrm{PE}$, respectively to attain the same contaminat removal efficiencies (Cooper, 2005; Vymazal, 2005; Kadlec, 2009).

- Poor maintenance or design can lead to excessive clogging, which can affect hydraulics and treatment performance (Knowles et al., 2011).

Since the implementation of the Water Framework Directive 2000/60/EC (EC, 2000a), as well as the Directive 91/271/CEE concerning urban wastewater treatment (EC, 1991), there is a need to comply with stringent regulations in many countries around Europe, especially for the treatment of small communities. This has attracted the focus to decentralized wastewater treatment ecotechnologies, existing an increasing demand for economical, aesthetic and ecologically sustainable treatment systems.

To this regard CWs, and other biological treatment technologies such as waste stabilization ponds, require very low to no energy consumption, and are easy to operate. Thus, they constitute a good alternative for wastewater treatment in small communities. Indeed, constructed wetlands have been extensively used at full-scale across the world since the 80s, for the treatment of not only municipal wastewater but all kinds of wastewater including stormwater, landfill leachate, tannery wastewater, and other industrial wastewaters (Schulz et al., 2001; Behrends et al., 2007; Nivala et al., 2007; Vymazal, 2009). They have been widely implemented in countries like France (Molle et al., 2005), UK (Weedon, 2003; Cooper, 2005), Denmark (Brix and Arias, 2005) or Czech Republic (Vymazal, 2002), and their implementation is increasing in countries like Spain (Vera et al., 2011) or Italy (Masi et al., 2007). Numerous studies have shown their capability to maintain hydraulic, technical, economic, environmental and ecological benefits (Vymazal, 2002; Dixon et al., 2003; Zhou et al., 2009).

There are several types of constructed wetlands. They can mainly be divided into subsurface flow (horizontal or vertical), surface flow constructed wetlands, and hybrid systems, which are a combination of different types. 


\subsection{Horizontal subsurface flow constructed wetlands}

This type of wetlands consist of gravel beds planted with wetland vegetation, where the wastewater is intended to remain below the top of the substrate and to flow horizontally in and around the roots and rhizomes of the plants. These wetlands are always flooded and water depth usually remains between 0.3 and $0.9 \mathrm{~m}$ (between 0.05 and $0.1 \mathrm{~m}$ beneath the surface of the bed). The recommended organic loading rate (OLR) is around $6 \mathrm{~g}$ of biochemical oxygen demand $\left(B_{5}\right) \mathrm{m}^{-2} \mathrm{~d}^{-1}$ (García and Corzo, 2008). The biofilm that grows on the granular media and the roots and rhizomes of the vegetation plays a major role in the removal of contaminants from wastwater.

Horizontal subsurface flow (HF) constructed wetlands are typically composed by: inlet piping, an impervious liner, filter media, emergent vegetation and outlet piping. A diagram of a conventional HF wetland is depicted in Fig. 2.1.

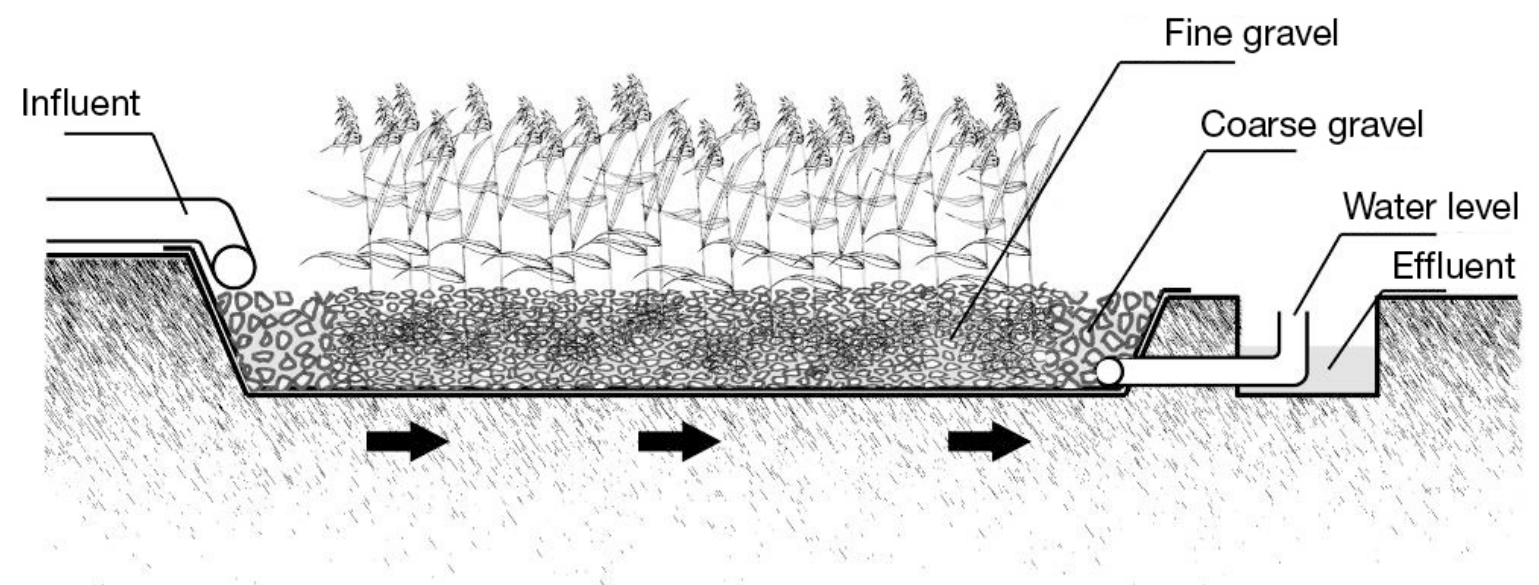

Figure 2.1. Horizontal subsurface flow constructed wetland schematic (adapted from Pedescoll, 2010).

They are good for total suspended solids (TSS), $\mathrm{BOD}_{5}$ and bacteria removal and denitrification. However, they are poor at nitrification because of limited oxygen transfer capacity (OTC) (Cooper, 1999; Tyroller et al., 2010). Since the water is not exposed, the risk associated with exposure to pathogenic organisms is minimized and they do not provide suitable habitat for mosquitos (Kadlec and Wallace, 2009).

\subsection{Vertical subsurface flow constructed wetlands}

In this type of wetlands water is distributed across the surface of a sand or gravel bed planted with emergent vegetation, and the effluent is collected from the bottom of the media, where the water is freely draining. The treatment of the water occurs as it percolates through the filter media and the plant root zone.

There exist several variations of vertical subsurface flow (VF) wetlands. In the most common design the bed is usually comprised of several layers of different grain size and contains a network of draining perforated pipes. They are usually fed intermittently and frequently loading and resting periods are applied. This is the case of many systems in France, where 2 or 3 beds work alternatively. In the French VF systems, the wastewater is fed without a previous primary treatment (Molle et al., 2008), causing the accumulation of a layer of solids on the top of the bed, which in turn acts as a filter. The alternation of cycles of feed and rest promote mineralization of the solid deposits during resting phases (Molle et al., 2005). In VF wetlands in general -usually comprised of a single bed-, it is the special operating conditions (i.e. intermittent dosing and unsaturated bed) that allow a higher organic loading rate to be applied in comparison to HF beds. Applied OLR values vary significantly from place to place and range from $20 \mathrm{~g} \mathrm{BOD}_{5} \mathrm{~m}^{-2} \mathrm{~d}^{-1}$ in Denmark (Brix and Arias, 2005) up to $180 \mathrm{~g} \mathrm{BOD}_{5} \mathrm{~m}^{-2} \mathrm{~d}^{-1}$ in French VF systems (just screened wastewater). The components of a typical VF wetland are shown in Fig. 2.2. 


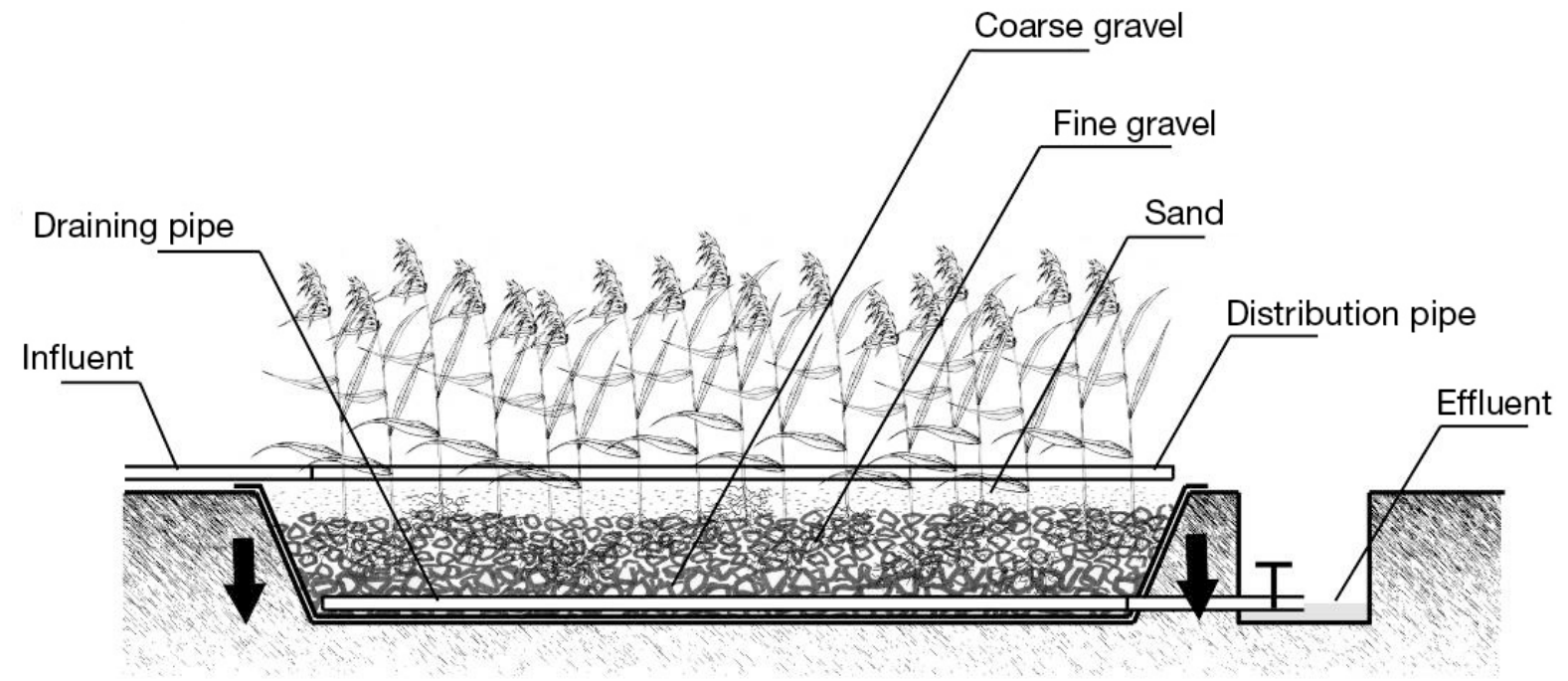

Figure 2.2. Basic elements of a vertical subsurface flow constructed wetland (adapted from Pedescoll, 2010).

The configuration of these systems confers very different properties to those of HF wetlands. They have a much greater OTC than HF beds, which makes them good for nitrification. Oxygen transfer is achieved by means of diluted oxygen present in wastewater, convection while intermittent loading, and diffusion processes occurring between doses (Torrens et al., 2009). The high OTC also leads to good removal of $\mathrm{BOD}_{5}$ and chemical oxygen demand (COD); they are also able to remove some bacteria (Headley et al., 2013) and are also considerably smaller (about 2-3 $\mathrm{m}^{2} / \mathrm{PE}$ ) than HF systems (about $5 \mathrm{~m}^{2} / \mathrm{PE}$ ) (Cooper, 2005; Vymazal, 2005). Nevertheless, they are less good for suspended solids removal and, more specially for single VF systems were no resting periods are allowed, clogging of the media may occur rapidly if the granular material selection and the hydraulic loading rates are not correct (Cooper, 1999; Platzer and Mauch, 1997; Kayser and Kunst, 2005).

\subsection{Free water surface wetlands}

In this type of wetlands, the wastewater flows above the top of the media (with some kind of impervious layer underneath), which can be of many types (e.g. clay, soil, gravel, etc.), since the wastewater is not intended to be filtered through it. These wetlands contain areas of open water, floating vegetation, and emerging plants, either by design or as an unavoidable consequence of the design configuration. A schematic of a conventional FWS wetland is depicted in Fig. 2.3 .

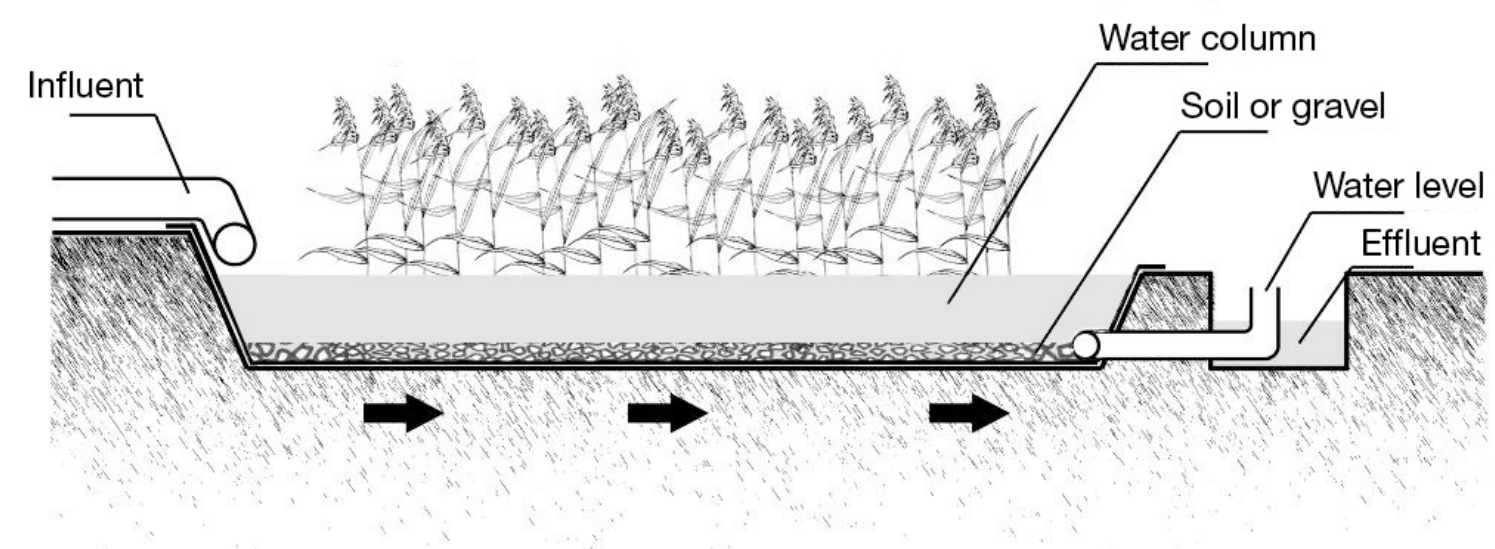

Figure 2.3. Free water surface constructed wetland schematic (adapted from Pedescoll, 2010).

Because the water is exposed during the treatment process, it is common that these types of wetlands attract a variety of wildlife (i.e. insects, mollusks, fish, amphibians, reptiles, birds and mammals) (Kadlec and Knight, 1996). Moreover, 
since they represent a risk for public health due to human exposure to pathogens, they are commonly applied for tertiary treatment of secondary or tertiary treatment effluents (e.g. activated sludge systems, waste stabilization ponds, SSF wetlands, etc.). They are especially appropriate for restoration of deteriorated areas or attenuation of agricultural runoff at tertiary treatment level (Thiere et al., 2009; Matamoros et al., 2012a; Matamoros and Salvadó, 2012).

\subsection{Hybrid systems}

Various types of constructed wetlands may be combined in order to achieve higher treatment efficiency, especially for nitrogen and pathogens. These hybrid systems are normally comprised of VF and HF systems arranged in different possible manners. While in HF wetlands nitrification is not achieved due to a lack of oxygen, VF wetlands can provide good conditions for nitrification but no denitrification occurs in these systems. Thenceforward, the strengths and weaknesses of each type of system balance each other out and in consequence it is possible to obtain an effluent low in BOD and in total nitrogen (TN) concentrations (Vymazal, 2005). Different combinations are possible, including HF followed by VF wetlands, VF followed by HF wetlands and other stages of filters including water recirculation from one stage to another (Brix and Arias, 2005).

\section{Removal and behavior of pharmaceuticals and personal care products in constructed wetlands for urban wastewater treatment}

The elimination of pharmaceuticals and personal care products (PPCPs) in constructed wetlands (CWs) takes place as a result of the simultaneous occurrence of various removal mechanisms, including biodegradation, adsorption, photodegradation, plant uptake, or hydrolysis. Some removal mechanisms will predominate in some wetland configurations in respect to others (e.g. photodegradation will only take place in free water surface (FWS) wetlands).

Average removal efficiencies of target PPCPs at several pilot and full-scale CW systems of different configurations are shown in Table 3.1.

Table 3.1. Average removal efficiencies (R.E.) of various pharmaceuticals and personal care products at different pilot and full-scale constructed wetland systems of various configurations.

\begin{tabular}{|c|c|c|c|c|}
\hline Compound & Range & $\begin{array}{l}\text { Avg R.E. } \\
\text { (\%) }\end{array}$ & Type of treatment & Ref. \\
\hline \multirow[t]{5}{*}{ Ibuprofen } & $95-96$ & 96 & Restoration FWS wetland (receives secondary effluent from a WWTP) & 1 \\
\hline & $\begin{array}{l}48 \text { (shallow)- } \\
81 \text { (deep) }\end{array}$ & n.a. & Pilot-scale HF wetlands (different depths) with injection of contaminants & 2 \\
\hline & n.a. & 99 & Experimental pilot -scale VF wetland $\left(5 \mathrm{~m}^{2}\right)$ & 3 \\
\hline & n.a. & $<15$ & $\begin{array}{l}\text { Restored wetland system fed with natural waters impacted by urban and } \\
\text { agricultural run-off }\end{array}$ & 4 \\
\hline & n.a. & $>95$ & Pilot-scale VF wetland $\left(5 \mathrm{~m}^{2}\right)$ & 5 \\
\hline \multirow[t]{6}{*}{ Diclofenac } & n.a. & 73 & Experimental pilot -scale VF wetland $\left(5 \mathrm{~m}^{2}\right)$ & 3 \\
\hline & n.a. & $<15$ & $\begin{array}{c}\text { Restored wetland system fed with natural waters impacted by urban and } \\
\text { agricultural run-off }\end{array}$ & 4 \\
\hline & n.a. & 65 & Pilot-scale VF wetland $\left(5 \mathrm{~m}^{2}\right)$ & 5 \\
\hline & $65-87$ & 77 & Three hybrid treatment Systems (ponds and CWs) & 6 \\
\hline & 73-96 & n.a. & FWS wetland (receives secondary effluent from WWTP) & 7 \\
\hline & n.a. & 21 & Household HF wetland & 8 \\
\hline Acetaminophen & $>90$ & $>90$ & Pilot—scale VF wetland $\left(5 \mathrm{~m}^{2}\right)$ & 5 \\
\hline Tonalide & $88-90$ & 89 & Restoration FWS wetland (receives secondary effluent from a WWTP) & 1 \\
\hline
\end{tabular}




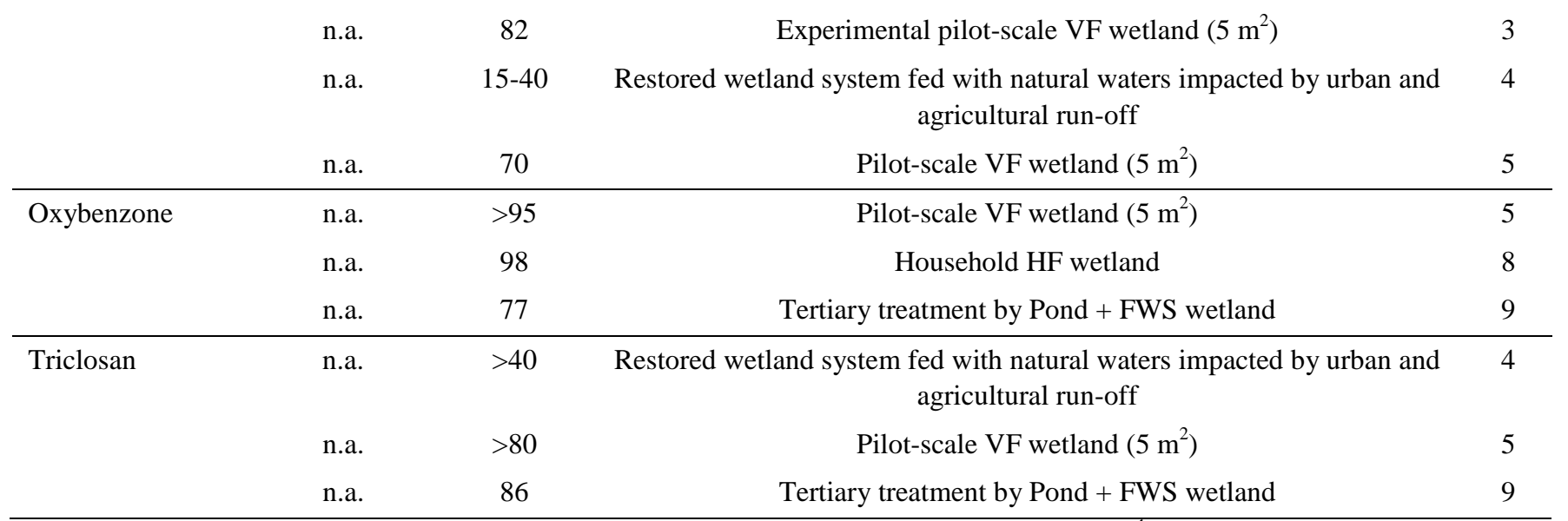

1. Llorens et al. (2009); 2. Matamoros et al. (2005); 3. Matamoros et al. (2007); 4. Matamoros et al. (2012a); 5. Ávila et al, 2014c; 6. Hijosa-Valsero et al. (2010a); 7. Matamoros et al. (2008b); 8. Matamoros et al. (2009a); 9. Matamoros and Salvadó (2012).

The anti-inflammatory drug ibuprofen (IB) has shown to be readily removed in the three types of CWs (HF, VF and FWS). Results by Matamoros et al. (2005) and Matamoros and Bayona (2006) show high removal efficiencies in HF wetlands (60 - 80\%), observing that the elimination rates are higher in shallower $(0.27 \mathrm{~m})$ than deeper beds $(0.5 \mathrm{~m})$. Matamoros et al. (2008a) found a prevalence of OH-IB over Ca-IB metabolite in a HF wetland, which would be explained by its predominant aerobic biodegradation. A comparison between different seasons by Hijosa-Valsero et al. (2011b) in HF beds shows a seasonal variability, with lower removal efficiencies in winter $(<40 \%)$ than in summer $(>90 \%)$. Moreover, two injection experiments carried out at that same experimental plant in Barcelona, Spain, showed how its removal highly depended on the existence of a high redox status, which would promote aerobic biodegradation of this drug (Ávila et al., 2010, 2013a). The removal of IB is also high in FWS wetlands, as documented by Llorens et al. (2009) and Matamoros et al. (2008b), where efficiencies of over $90 \%$ are detected. High elimination rates were also reported for VF beds, with efficiencies of around 99\% for unsaturated vertical wetlands (Matamoros et al., 2007).

Conversely, although diclofenac (DCF) has been reported to be recalcitrant in activated sludge wastewater treatment plants (WWTPs) (Heberer, 2002), this substance shows a variable removal in CWs, ranging from values as low as $21 \%$ in HF beds (Matamoros et al., 2009a; Matamoros and Bayona, 2006) up to values of 99\% at experimental scale HF wetland under an injection experiment (Ávila et al., 2010) or a value of 73\% in a VF wetland in Denmark (Matamoros et al., 2007). In FWS wetlands average removal efficiencies have been reported to be as high as $96 \%$ and $73-96 \%$ in studies carried out by Llorens et al. (2009) and Matamoros et al. (2008b), respectively. This could be attributed to its large removal through photodegradation, as reported by Andreozzi et al. (2003). This substance is fairly hydrophilic and was not detected in the particulate matter associated to the gravel matrix of CWs, as reported by Matamoros and Bayona (2006). A high variability on the elimination of diclofenac was also observed by Hijosa-Valsero et al. (2011b) in various experimental meso-scale HF wetlands, who showed that its degradation was favored by high temperatures (summer VS winter) and found variable removal efficiencies in Barcelona (around $70 \%)$ and in León $(<12 \%)$ wetlands. Although reductive dehalogenation has been claimed as a possible important removal mechanism for this compound (Ávila et al., 2010), other studies show how its removal seems to be enhanced by more oxidizing conditions (Ávila et al. 2013a).

In regards to the removal of the estrogen ethynilestradiol in CWs, Gray and Sedlak (2005) found a $41 \%$ removal after spiking it in concentrations slightly above background concentrations in a full-scale FWS wetland $\left(750 \mathrm{~m}^{2}\right)$ with a depth of $0.5 \mathrm{~m}$ and a hydraulic retention time of $84 \mathrm{~h}$, and reported sorption as a major mechanism for its removal in the aqueous phase. Song et al. (2009) evaluated the influence of saturated vs. unsaturated conditions in VF units in regards to the removal of estrogens, and found out that unsaturated conditions (and thus more oxidized conditions) were better for the removal of this type of pollutants.

What is more, the fate of the musk fragrance tonalide in constructed wetlands has been previously investigated by several authors, such as Matamoros et al. (2008b) who reported elimination rates of $88-90 \%$ in a full-scale FWS wetland, which did not show a dependence on the season, presumably due to their low biodegradability properties (i.e. major removal mechanism through interaction with organic matter and sediment). In fact, in another study, this time in two pilot HF wetlands at Les Franqueses del Vallès (Barcelona), Matamoros and Bayona (2006) found this fragrance together with galaxolide to be the most abundant on the gravel bed and the suspended particulate matter, attributing the 
removal of these musks to hydrophobic interactions with the organic matter and the biofilm. Moreover, no water depth effect dependence was found for this compound. On the contrary, Hijosa-Valsero et al. (2011b) reported a possible dependence of this compound on temperature, since the removal efficiencies were significantly higher in summer than in wintertime, presumably due to the release of hydrophobic compounds in winter (i.e. galaxolide and tonalide), under a lower biofilm and plant activity. Removal efficiencies in VF wetlands were also reported by Matamoros et al. (2007) to be moderately removed with elimination rates ranging from $75-82 \%$.

The behavior of the sunscreen agent oxybenzone in CWs has been reported by Matamoros et al. (2007) in a VF wetland, where it was very efficiently removed ( $>95 \%$ ), and by Matamoros et al. (2009a), where the removal was also $>95 \%$ in HF wetlands and $90 \%$ in VF wetlands. The authors suggest that it could be partially removed by sorption onto the particulate matter, although it is majorly removed by biodegradation (Ávila et al., 2013a, 2014b).

In regards to the elimination of triclosan, Park et al. (2009) reported removal efficiencies in FWS wetlands in South Korea of above $60 \%$. Matamoros et al. (2012a) found triclosan to be the substance achieving the highest removal efficiency (>40\%) among all studied compounds in a restored wetland in Denmark.

\subsection{Design and operational factors affecting the removal of pharmaceuticals and personal care products in constructed wetlands}

The removal of contaminants in CWs occurs as a result of complex physico-chemical and microbial interactions. The rates of these processes depend on a variety of design and operational factors such as depth of the bed, type and size of media, hydraulic and organic loading rates, feeding strategy and artificial/external aeration, among others. The design of CWs is often carried out using the black box concept, and reduced treatment efficiency may occur when wetlands are constructed without considering the influence of these parameters. Most of the available research concerning design and operational parameters' influence on treatment performance focuses on conventional water quality parameters. Only in the last decade, the effect of these parameters on the removal of pharmaceuticals and personal care products (PPCPs) has been investigated. Those include very few studies evaluating the influence of water depth (Matamoros et al., 2005; Matamoros and Bayona, 2006); primary treatment (Ávila et al., 2013a), operation under cycles of saturation/unsaturation (Ávila et al., 2013a); type of organic matter (Matamoros et al., 2008a); type of granular media (Dordio et al., 2009, 2010) and other different design parameters and modes of operation (Hijosa-Valsero et al., 2010b, 2011b; Zhang et al., 2012a,b; Ávila et al., 2014b). Therefore the optimization of the performance of CWs in terms of PPCP removal stands as a necessity that can be achieved through the identification of the optimal design and operational factors of these treatment systems.

\subsubsection{Behavior of PPCPs in horizontal subsurface flow constructed wetlands}

HF wetlands display seasonal effects for PPCP removal, with lower removal efficiencies during the cold season at lower water temperatures. Seasonal patterns have been observed at various CW systems at mesoscale in Barcelona, NE Spain (Hijosa et al., 2011b; Ávila et al., 2013a) and in León, NW Spain (Hijosa et al., 2010b; Reyes-Contreras et al., 2012), being removal efficiencies consistently better in summer than in winter for almost all of the studied PPCPs.

It is generally known that microbial activity is highly influenced by temperature. Microorganisms in wetlands usually reach their optimal activity at warm temperatures $\left(15-25^{\circ} \mathrm{C}\right)$, especially nitrifying and proteolytic bacteria (Truu et al., 2009). The same trend has been found to occur for denitrifying bacteria (Spieles and Mitsch, 2000; Boulêtreau et al., 2012). The elimination of PPCPs has been found to depend on water temperature, being especially important for biodegradable compounds (e.g. ibuprofen, diclofenac). Moreover, the presence of vegetation during the summer season, could also contribute to the removal of PPCPs, either by plant assimilation, and to a higher extent by the transfer of oxygen to the rhizosphere (Brix, 1993; Tyroller et al., 2010). This should allow the creation of microenvironments with different redox conditions, which in turn would promote the development of microbial biofilms with functionally different respiration processes (Wiessner et al., 2005; Kadlec and Wallace, 2009; Ávila et al., 2013a).

What is more, it is also widely known that removal of most pollutants, including PPCPs, in CWs occur primarily due to microbial activity (García et al., 2010). In fact, the removal efficiency of PPCPs in CWs is oftentimes higher than that 
achieved in conventional wastewater treatment plants (WWTPs), which could presumably be due to their higher microbial diversity occurring in wetland ecosystems (Kadlec and Wallace, 2009). CWs can be designed to favor a wide range of redox conditions, therefore enhancing a variety of biological processes and removal of multiple contaminants in the same CW bed. In turn, CW technology can be optimized if the factors influencing their performance are identified.

For instance, operating HF wetlands in batch (or cycles of fill and drain) seems to be a very important factor promoting the elimination of most contaminants. The alternation of phases of saturation and unsaturation promotes the existence of a higher redox status as compared to functioning under saturated conditions, which in turn enhance significantly the elimination of PPCPs (Zhang et al., 2012b; Ávila et al., 2013a). Substances whose major removal mechanism is thought to be biodegradation under aerobic conditions (e.g. ibuprofen) are those that show the largest differences (Ávila et al., 2013a). In general, the operation under cycles of saturation and unsaturation seems to be a good strategy to enhance the treatment performance of HF CWs by promoting the fluctuation of redox conditions where robust aerobic facultative biofilms can operate (Stein et al., 2003; Faulwetter et al., 2009).

Other design factors for HF wetlands are water depth, applied hydraulic loading rate, grain size and type of media. In particular, water depth seems to be a determining factor in this type of wetlands, which affects the redox conditions, oxygen supply and thus the treatment performance of the wetlands. Shallower wetlands appear to have higher redox potential and thus promote more variate and energetically favorable reactions, which in turn enhance the degradation of PPCPs (Matamoros et al., 2005). Other authors have shown experimental evidence, which support this hypothesis (García et al., 2003a, 2005; Headley and Davison, 2005; Huang et al., 2005; Matamoros and Bayona, 2006).

In regards to the granular media of HF beds, in general a wide range of materials and sizes have been applied around the world, and its selection is in many cases dictated by the availability, price and local practices of a certain region. Some studies indicate the importance of using hard, durable and homogeneous materials that do not contain fine grains, which might clog the media (García and Corzo, 2008; Pedescoll et al., 2009). In general, finer materials $\left(D_{60}=3.5\right.$ vs. $10 \mathrm{~mm}$ ) have been recommended in HF beds when low organic loads are applied since they provide a greater surface area for microbial biofilms. Finer gravel promotes a higher growth of the vegetation and in conjunction a higher removal of pollutants such as ammonia (García et al., 2005). However, it is important to have in mind that the finer the material, the greater the risk of clogging and hydraulic problems. Moreover, although usually granite gravel is used in HF wetlands, other alternative sorbents have emerged so as to increase the adsorption capacity of these wetlands, such as light expanded clay aggregates (Dordio et al., 2009, 2010). This is expected to be especially important for hydrophobic compounds such as fragrances. The influence of granular size in HF wetlands' PPCPs removal has not to date been assessed, though it should majorly show effects on hydrophobic substances that get attached to particulate matter.

Finally, it is well known that in HF wetlands the oxygen demand exerted by the degradation of pollutants in wastewater exceeds the amount of oxygen available within the wetland bed. In general, subsurface oxygen limitation is one of the main rate-limiting factors for traditional HF wetlands (Brix and Schierup, 1990; Kadlec and Wallace, 2009; Tyroller et al., 2010). For that reason, other variants such as the use of active aeration are being developed and implemented worldwide and have shown to enhance the treatment performance of this type of CWs (Wallace, 2001; Nivala et al. 2013). However, this practice come at a heavy operational and maintenance cost, which is only justified if the improvement in the performance of the wetland offsets the cost of operation equipment and energy needs (Kadlec and Wallace, 2009; Nivala et al., 2012). To the best of our knowledge there are still no studies, which assess the removal of PPCPs within actively aerated HF wetlands.

In conclusion, seasonal variations in environmental conditions are relevant factors to take into consideration for HF CW design, and operation and maintenance (O\&M), especially at places showing high seasonality. In general, it has been observed that the treatment performance of HF CWs on PPCP removal is enhanced by the adoption of strategies that promote a higher redox status of the system. Operating HF wetlands in cycles of saturation and unsaturation stands as a very relevant strategy, which greatly enhances PPCP removal by promoting a higher redox status of the wetland bed. Water depth is also a critical factor influencing performance, being shallower wetlands of about $0.25-0.30 \mathrm{~cm}$ more efficient in PPCP removal than deeper HF CWs. 


\subsubsection{Behavior of PPCPs in vertical subsurface flow constructed wetlands}

In general, it has been observed that vertical subsurface flow (VF) wetlands are more efficient on the removal of PPCPs than horizontal subsurface flow (HF) wetlands, which agrees with other laboratory and experimental studies which suggest that aerobic pathways are in general more efficient in the degradation of these substances than anaerobic ones (Zwiener and Frimmel, 2003; Matamoros et al., 2007; Conkle et al., 2012; Ávila et al., 2013a). However, the relative importance of a particular degradation process in VF CWs can vary as a function of environmental factors, organic contaminant being treated, wetland configuration, and specific design and operational parameters. For instance, in unsaturated intermittently-loaded VF wetlands (typical), diffusion and convection processes depend on the loading strategy, being affected by the number of pulses, the volume of the pulse, and the duration of surface filter dewatering (Molle et al., 2006; Torrens et al., 2009). The choice of the filter media (i.e. grain size, grain material, depth of layers) is also crucial, and should simultaneously satisfy treatment needs, while avoiding clogging of the bed and maintaining oxygen renewal in the media (Cooper, 2003; Kayser and Kunst, 2005).

In regards to the loading frequency, a higher volume of batch dosed at lower feeding frequencies should favor oxygen transfer into the media due to diffusion and mass convection. However, if the volume is too high, it could lead to decreased removal efficiency due to reduced contact time between the water and the biomass. On the other hand, if the loading is done too frequent, the capacity of oxygen renewal occurring between pulses could be limited, thus affecting removal processes such as nitrification. To this respect, differences could be more notable in the long-term (Molle et al., 2006; Torrens et al., 2009). Further studies in this direction are needed.

In general, the loading frequency is an important operational parameter to guarantee the good treatment performance of this type of treatment systems, where sufficient oxygen renewal and mineralization of the organic matter should be allowed. Applied hydraulic loading rates (HLRs) and potential accumulation of solid deposits on the bed surface should be carefully supervised and controlled, especially in non-rested VF wetlands, so as to avoid filter clogging and surface ponding, which could eventually decrease the efficiency and lifetime of the treatment system (Platzer and Mauch, 1997; Langergraber et al., 2003).

Moreover, grain size is again an important factor to take into account. A recent study has evaluated the influence of this factor on PPCP removal and has shown a greater performance of sand-based (1-3 mm) than gravel-based (4-8 mm) VF wetlands (Ávila et al., 2014c). Results suggest that in gravel-based VF wetlands, lower contact together with lower solids retention capacity due to higher pores between grains would result in reduced treatment efficiency. In fact, it has been observed that a rapid flow downwards does not favor ammonia sorption onto the gravel bed, which might eventually decrease nitrification activity (Molle et al., 2006; Torrens et al., 2009). The lower surface area per unit volume in gravel-based as compared to sand-based VF beds, provided by a larger grain size, reduces oxygen diffusion and entrapment of solids, and may provide insufficient contact time between the biofilm and pollutants. On the other hand, in sand-based VFs, the higher surface area for biofilm attachment and higher oxygen availability may promote the existence or larger biomass and more diverse microbial communities. In fact, higher microbial biomass and activities have been found to take place in the upper part (about first $10 \mathrm{~cm}$ of a $50 \mathrm{~cm}$ VF) of a VF wetland, where a higher redox status prevails (Tietz et al., 2007).

Although higher elimination rates have been found at sand-based systems (Ávila et al., 2014c), their long-term operation may make them more vulnerable to clogging. In practice, grain size as well as loading frequency should be carefully selected, as well as HLRs controlled (Matamoros et al., 2007), in order to ensure desired removal of PPCPs, as well as enough oxygen renewal and mineralization of organic matter so that no clogging develops in the filter beds. Nevertheless, in French-style VF wetlands, where various beds alternate cycles of feed and rest, it has been observed that very high hydraulic overloads can be applied without observing a decreased in the infiltration capacity or treatment performance of the system (aprox. 0.4-1.8 $\mathrm{m} \mathrm{d}^{-1}$ ). Nevertheless, in particular case scenarios the grain and type of media used should be adapted to available local materials, and the use of gravel could constitute an acceptable solution. 


\subsection{Behavior of pharmaceuticals and personal care products in hybrid constructed wetland systems}

With the purpose of evaluating the treatment capacity and possible performance enhancement when various CW of different types are combined, a hybrid constructed wetland system consisting of three stages of VF, HF and FWS wetland (in this study followed by an open-air water tank indicated for water reuse) was designed, constructed and monitored at experimental and full-scale for the removal of conventional water quality parameters and PPCPs (Ávila et al., 2013b, 2014a,b).

Results obtained in a full-scale hybrid system of the cited characteristics (surface areas of $317 \mathrm{~m}^{2}, 219 \mathrm{~m}^{2}$ and $240 \mathrm{~m}^{2}$ for the VF, HF and FWS wetlands, respectively) showed to perform remarkably well in the removal of PPCPs, achieving very high overall removal efficiencies for the majority of the studied compounds (above $80 \%$ removal for all compounds) (Ávila et al., 2014a). The accumulated removal efficiencies in each treatment unit are displayed in Fig. 3.1.

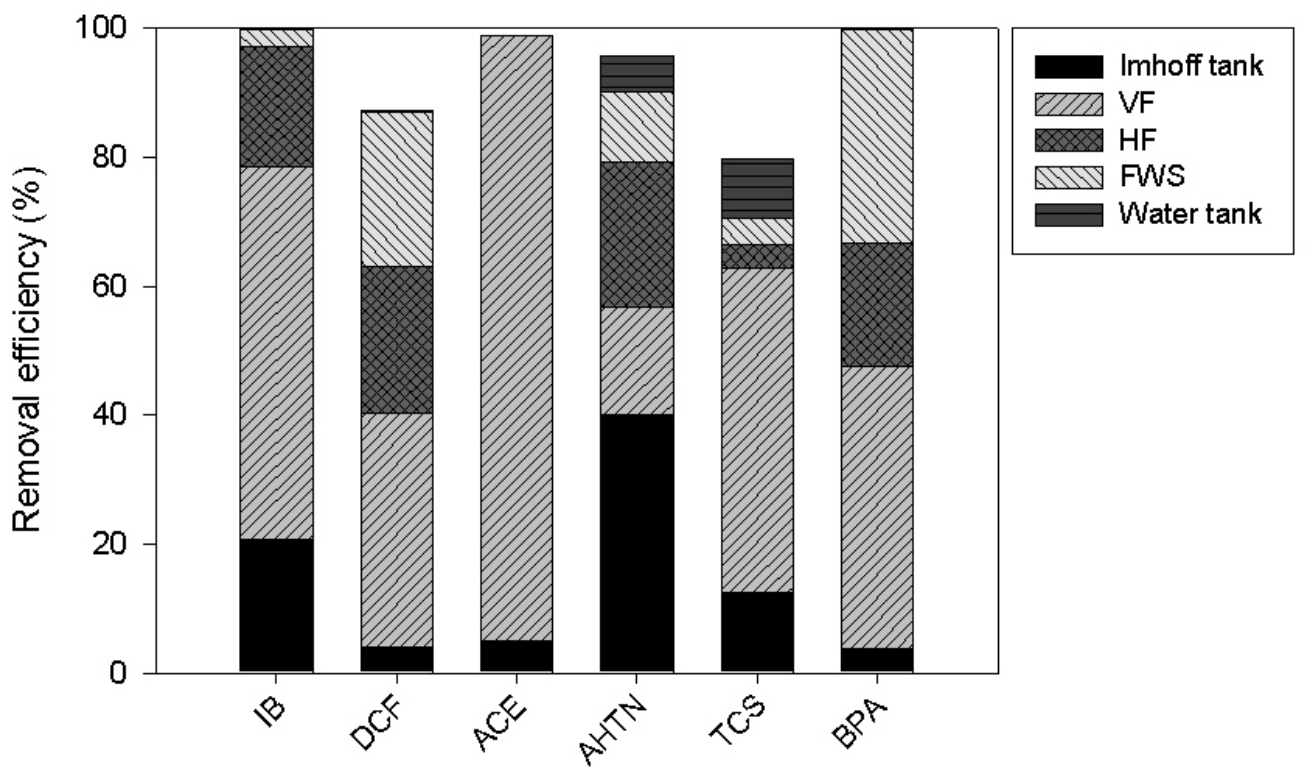

Figure 3.1. Accummulated removal efficiencies of various pharmaceuticals and personal care products at the different units of the pilot hybrid treatment system (Ávila et al., 2014a). Note: ibuprofen -IB-; diclofenac -DCF-; acetaminophen -ACE-; tonalide AHTN-; triclosan -TCS-; the industrial chemical compound bisphenol A -BPA-.

Final effluent concentrations of target PPCPs were very low, being below the limit of detection for acetaminophen. The rest were in the ng $\mathrm{L}^{-1}$ order (20-100), which is in the range of those found in the environment, such as those reported by Matamoros et al. (2009b) in small ponds or lagoons. These concentrations are also in the range of those obtained in advanced treatment technologies applied at full-scale, such as ozonation or membrane filtration (Snyder et al., 2007; Rosal et al., 2010).

The high removal efficiencies can be explained by differing existing physico-chemical conditions at different CW configurations, which would allow for the combination and synergy of various physicochemical and biological removal mechanisms to occur (e.g. biodegradation, sorption, volatilization, hydrolysis, and photodegradation) and thus achieve improved treatment efficiency of most pollutants (Faulwetter et al., 2009; Imfeld et al., 2009). In this sense, while aerobic metabolic pathways and solids retention are enhanced in VF wetlands, other removal mechanisms such as anaerobic biodegradation and sorption would predominate in HF beds. At last, the FWS wetland would be responsible for potential photodegradation of compounds, and less importantly through adsorption onto organic matter and uptake of plant material (Matamoros and Salvadó, 2012).

The superior treatment performance of the VF over the other treatment units could be owed to energetically favorable aerobic microbial reactions, as well as hydrolysis reactions, taking place within this wetland type and provided by its design and operation strategy, which results in high effluent redox potentials and dissolved oxygen concentrations. However, the synergic nitrification-denitrification activity observed in the VF bed within the cited (Ávila et al., 2014a) 
and a previous study at the same treatment plant (Ávila et al., 2013b) suggest the co-existence of both aerobic and anaerobic microenvironments within this wetland bed, which would allow the occurrence of both processes to take place. This could be partially explained by the occurrence of a saturated layer at the bottom of the wetland bed, below draining pipes. Similarly, this finding indicates that although aerobic biodegradation and sorption onto organic matter may be the major removal mechanisms contributing to PPCP reduction in VF wetlands, alternative processes based on anaerobic metabolism could simultaneously be occurring at anoxic microsites or micropores within the wetland bed (i.e. in lower layers) (Cooper et al., 1996; Ávila et al., 2010), which contribute to its elimination.

While substances like the musk fragrance tonalide show a great reduction within the HF presumably due to sorption processes, results for triclosan would exhibit little sorption capacity. The behavior of triclosan within the three different wetland configurations indicate aerobic biodegradation as the major removal mechanism involved in the elimination of this compound (Singer et al., 2002; Ying et al., 2007). Although triclosan has been detected in plant and sediments of a HF CW and its concentration generally decreased from inflow to outflow (Zárate et al., 2012), sorption and plant uptake does not appear to constitute a principal mechanism of triclosan removal in constructed wetlands. The similarly high removal efficiencies achieved for diclofenac in the current study in the HF bed if compared to the VF wetland suggest that various alternative mechanisms may determine the elimination of this compound, and to that respect, anaerobic biodegradation through reductive dehalogenation could constitute a predominant degradation pathway of diclofenac when anaerobic conditions prevail (Park et al., 2009; Ávila et al., 2010; Hijosa-Valsero et al., 2010a).

The FWS wetland performed especially well for diclofenac. These results support photodegradation as a principal removal mechanism involved in diclofenac attenuation in water bodies (Buser et al., 1998; Andreozzi et al., 2003; Matamoros and Salvadó, 2012, 2013), together with less predominant mechanisms (i.e. aerobic/anaerobic biodegradation, plant uptake). Although the removal of triclosan was negligible, some more reduction within the water reuse tank seemed to occur, indicating that photooxidation processes may constitute a small contribution to its removal (Mezcua et al., 2004; Ávila et al., 2014b; Matamoros and Salvadó, 2012, 2013). Although the reduction of tonalide concentrations in the FWS could be attributed to sorption onto particulate matter and sediment, further reduction was achieved at the water reuse tank, suggesting photodegradation through sunlight exposure as one of the principal mechanisms of the fragrance tonalide removal within this type of wetland configuration. Similarly high removal efficiencies were obtained at other FWS wetlands operating as a tertiary treatment step (Matamoros et al., 2008b; Llorens et al., 2009; Matamoros and Salvadó, 2012).

In conclusion, hybrid CW systems consisting of a combination of CW configurations, including a VF CW, a HF wetland, and a FWS wetland operating in series, has shown to be a very robust ecotechnology for wastewater treatment and reuse in small communities (Ávila et al., 2014a,b). The combination of different wetland configurations has shown to optimize a number of important treatment processes, achieving an excellent overall removal efficiency of PPCPs (above $80 \%$ for all studied substances), conventional water quality parameters ( $>90 \%$ ), as well as a high disinfection capacity (Ávila et al., 2013b). This has been possible thanks to the occurrence of complementary abiotic/biotic removal pathways taking place under differing physico-chemical conditions existing at wetlands of different configuration.

\section{Concluding remarks}

This chapter shows how pharmaceuticals and personal care products (PPCPs) are a subgroup within the so-called 'emerging organic contaminants' with comprise an extraordinarily diverse array of chemicals used in veterinary medicine, agricultural practice, human health and cosmetic care. PPCPs include prescription and non-prescription medications, nutritional supplements, diagnostic agents, as well as other consumer products such as disinfectants, fragrances, sunscreen agents and cosmetics. Even though most of them are polar, have a short half-lifetime in water, and are found in trace concentrations, they are considered pseudo-persistent pollutants. This is because of their universal, frequent usage by multitude of individuals and animals, which causes a continuos discharge into the environment oftentimes sourcing from either non-treated or insufficient wastewater treatment. Little is known about the degradation pathways and products of most PPCPs in the environment, and less is known about their intermediates of degradation, which just started to be explored. Conventional activated sludge wastewater treatment plants often provide insufficient removal of these substances, and in this context constructed wetlands constitute a good option for the removal of pharmaceuticals and care products from wastewater. 
Constructed wetlands emphasize the transformation processes taking place in natural wetlands to treat wastewater. Wetlands are complex ecosystems and comprise a wide range of microenvironments that aim at pollutant removal. Biodegradation, sorption and photodegradation seem to be the major mechanisms involved in PPCP removal in constructed wetlands. While aerobic biodegradation and sorption predominate in vertical flow wetlands, horizontal subsurface flow wetlands should be especially important at anoxic biodegradation and sorption of contaminants. In surface flow wetlands photodegradation plays a major role in PPCP removal. Other mechanisms such as hydrolysis, plant uptake, sedimentation, contaminant accumulation, metabolic transformation, or phytovolatilization also contribute at a lower rate to PPCP removal.

Constructed wetlands can be optimized so as to improve treatment performance. Design and operational factors such as water depth, hydraulic loading rate, grain size, or use of active aeration can have a major impact on the removal efficiency of PPCP removal. In general, vertical subsurface flow wetlands have shown to be more efficient on the removal of PPCPs than horizontal subsurface flow wetlands due to the aerobic environment promoted in the intermittently-fed, unsaturated typical vertical flow beds.

The use of hybrid constructed wetland systems, which combine different wetland types, has shown to enhance the removal of PPCPs by combining different treatment processes occurring at various (physico-chemical and microbiological) microsites of the different wetland units. A combination of vertical flow, horizontal flow and free water surface wetlands in series has proven to achieve very high removal rates (above 80\%) for most studied PPCPs, and constitutes a good alternative for the treatment of domestic wastewater in small or rural communities. 


\section{References}

AEMPS, 2006. Agencia Española de Medicamentos y Productos Sanitarios. Spanish Ministry of Health and Social Politics. Utilización de antiinflamatorios no esteroides (AINE) en España 1992-2006. [Available: http://www.aemps.gob.es/medicamentosUsoHumano/observatorio/docs/AINE.pdf [accessed 2 June 2013]].

AEMPS, 2009. Agencia Española de Medicamentos y Productos Sanitarios. Spanish Ministry of Health and Social Politics. Uso de antibióticos en España (1992-2009). [Available: http://www.aemps.gob.es/medicamentosUsoHumano/observatorio/docs/antibioticos.pdf [accessed 2 June 2013]].

Andreozzi, R., Marotta, R., Paxéus, N., 2003. Pharmaceuticals in STP effluents and their solar photodegradation in aquatic environment. Chemosphere 50, 1319-1330.

Ávila, C., Bayona, J.M., Aragón, C., Martín, I., Salas, J.J., García, J, 2014a. Emerging organic contaminant removal in a full-scale hybrid constructed wetland system for wastewater treatment and reuse. Ecological Engineering, submitted.

Ávila, C., Matamoros, V., Reyes-Contreras, C., Piña, B., Casado, M., Mita, L., Rivetti, C., Barata, C., García, J., Bayona, J.M., 2014b. Attenuation of emerging contaminants in a hybrid constructed wetland system under different hydraulic loading rates and their associated toxicological effects in wastewater. Science of the Total Environment 470-471, 1272-1280.

Ávila, C., Nivala, J., Olsson, L., Kassa, K., Headley, T., Bayona, J.M., García, J. 2014c. Influence of media size, loading frequency and use of active aeration on the removal of emerging organic contaminants in vertical subsurface flow constructed wetlands. Science of the Total Environment, submitted.

Ávila, C., Pedescoll, A., Matamoros, V., Bayona, J.M., García, J., 2010. Capacity of a horizontal subsurface flow constructed wetland system for the removal of emerging pollutants: An injection experiment. Chemosphere 81, $1137-1142$

Ávila, C., Reyes, C., Bayona, J.M., García, J., 2013a. Emerging organic contaminant removal depending on primary treatment and operational strategy in horizontal subsurface flow constructed wetlands: Influence of redox. Water Research 47, 315-325.

Ávila, C., Salas, J.J., Martín, I., Aragón, C., García, J., 2013b. Integrated treatment of combined sewer wastewater and stormwater in a hybrid constructed wetland system in southern Spain and its further reuse. Ecological Engineering $50,13-20$

Balmford, A., 2013. Pollution, politics and vultures. Science 339 (6120), 653-654.

Barceló, D., 2003. Emerging pollutants in water analysis. Trends in Analytical Chemistry 22, 14-16.

Barceló, D., Petrović, M., 2007. Pharmaceuticals and personal care products (PPCPs) in the environment. Analytical and Bioanalytical Chemistry 387, 1141-1142.

Behrends, L.L., Balley, E., Jansen, P., Houke, L., Smith, S., 2007. Integrated constructed wetland systems: design, operation, and performance of low-cost decentralized wastewater treatment systems. Water Science and Technology 55, 155-161.

Benitez, F.J., Acero, J.L., Real, F.J., Roldan, G., Rodriguez, E., 2013. Photolysis of model emerging contaminants in ultra-pure water: kinetics, by-products formation and degradation pathways. Water Research 47, 870-880.

Bergman, Å., Heindel, J.J., Jobling, S., Kidd, K.A., Zoeller, R.T. (Eds.), State of the science of endocrine disrupting chemicals - 2012. United Nations Environment Programme and the World Health Organization. Geneva, Switzerland, 2013. [Available: http://www.who.int/ceh/publications/endocrine/en/index.html [accessed 4 March 2013]].

Boulêtreau, S., Salvo, E., Lyautey, E., Mastrorillo, S., Garabetian, F., 2012. Temperature dependence of denitrification in phototrophic river biofilms. Science of the Total Environment 416, 323-328.

Buser, H.R., Poiger, T., Müller, M.D., 1998. Occurrence and fate of the pharmaceutical drug diclofenac in surface waters: rapid photodegradation in a lake. Environmental Science and Technology 32, 3449-3456. 
Brix, H., 1993. Macrophyte-mediated oxygen transfer in wetlands: transport mechanisms and rates. In: Constructed welands for water quality improvement, Moshiri G.A. (ed.) Lewis Publishers: Boca Raton, Florida, pp. 391-398.

Brix, H., Arias, C., 2005. The use of vertical flow constructed wetland for on-site treatment of domestic wastewater: New Danish guidelines. Ecological Engineering 25, 491-500.

Brix, H., Schierup, H.H., 1990. Soil oxygenation in constructed reed beds: the role of macrophyte and soil-atmosphere interface oxygen transport. In: Constructed Wetlands in Water Pollution Control. Cooper P.F., Findlater, B.C., (Eds). Pergamon Press: Oxford, United Kingdom. pp. 53-66.

Brooks, B.W., Berninger, J.P., Kristofco, L.A., Ramirez, A.J., Stanley, J.K., Valenti, T.W., 2012. Chapter Eight Pharmaceuticals in the Environment: Lessons learned for reducing uncertainties in Environmental Risk Assessment. Progress in Molecular Biology and Translational Science 112, 231-258.

Cadby, P.H., Troy, W.R., Vey, M.G.H., 2002. Consumer exposure to fragrance ingredients: Providing estimates for safety evaluation. Regulatory Toxicology and Pharmacology 36, 246-252.

Campbell, J., 2007. Drugs on tap: Pharmaceuticals in our drinking water. Pharmacy Practice. [Available: http://www.cielap.org/pdf/news.DrugsOnTap.pdf [accessed 17 May 2010]].

Carballa, M., Omil, F., Lema, J.M., 2005. Removal of cosmetic ingredients and pharmaceuticals in sewage primary treatment. Water Research 39, 4790-4796.

Carballa, M., Omil, F., Lema, J. M., Llompart, M., García-Jares, C., Rodríguez, I., Gómez, M., Ternes, T., 2004. Behavior of pharmaceuticals, cosmetics and hormones in a sewage treatment plant. Water Research 38, 29182926.

Chen, F., Ying, G.G., Kong, L.X., Wang, L., Zhao, J.L., Zhou, L.J., Zhang, L.J., 2011. Distribution and accumulation of endocrine-disrupting chemicals and pharmaceuticals in wastewater irrigated soils in Hebei, China. Environmental Pollution 159, 1490-1498.

Clara, M., Strenn, B., Gans, O., Martinez, E., Kreuzinger, N., Kroiss, H., 2005. Removal of selected pharmaceuticals, fragrances and endocrine disrupting compounds in a membrane bioreactor and conventional treatment plants. Water Research 39, 4797-4807.

Conkle, J.L., Gan, J., Anderson, M.A., 2012. Degradation and sorption of commonly detected PPCPs in wetland sediments under aerobic and anaerobic conditions. Journal of Soils and Sediments 12, 1164-1173.

Connell, D.W., 2005. Basic concepts of Environmental Chemistry, Second Edition. Taylor \& Francis: Boca Raton, FL, USA. pp. 465.

Cooper, P., 1999. A review of the design and performance of vertical-flow and hybrid reed bed treatment systems. Water Science and Technology 40, 1-9.

Cooper, P.F., 2003. Sizing vertical flow and hybrid constructed wetland systems. In: Proceedings of the 1st International Seminar on the Use of Aquatic Macrophytes for Wastewater Treatment in Constructed Wetlands. Lisbon, Portugal. May 8-10.

Cooper, P., 2005. The performance of vertical flow constructed wetland systems with special reference to the significance of oxygen transfer and hydraulic loading rates. Water Science and Technology 51, 81-90.

Cooper, P.F., Job, G.D., Green, M.B., Shutes, R.B.E., 1996. Reed beds and constructed wetlands for wastewater treatment. WRc Swindon: UK, 184 pp.

Cunningham, V.L., Buzby, M., Hutchinson, T., Mastrocco, F., Parke, N., Roden, N., 2006. Effects of human pharmaceuticals on aquatic life: next steps. Environmental Science and Technology 40, 3456-3462.

Daughton, C.G., 2004a. Non-regulated water contaminants: Emerging research. Environmental Impact Assessment Review 24, 711-732.

Daughton, C.G., 2004b. PPCPs in the environment: future research - beginning with the end always in mind. In: Pharmaceuticals in the Environment, Second Edition. Kümmerer, K. (Ed.), Springer, Chapter 33, pp. 463-495. [Available: http://www.epa.gov/ppcp/pdf/daughton-needs.pdf [accessed 10 November 2009]]. 
Daughton, C.G., Ruhoy, I.S., 2013. Lower-dose prescribing: minimizing “side effects” of pharmaceuticals on society and the environment. Science of the Total Environment 443, 324-337.

Daughton, C.G., Ternes, T.A., 1999. Pharmaceuticals and personal care products in the environment: agents of subtle change? Environmental Health Perspectives 107, 907-938.

Díaz-Cruz, M.S., López de Alda, M.J., Barceló, D., 2003. Environmental behavior and analysis of veterinary and human drugs in soils, sediments and sludge. Trends in Analytical Chemistry 22, 340-351.

Dixon, A., Simon, M., Burkitt, T., 2003. Assessing the environmental impact of two options for small-scale wastewater treatment: comparing a reed bed and an aerated biological filter using a life cycle approach. Ecological Engineering 20, 297-308.

Dordio, A., Carvalho, A.J.P., Teixeira, D.M., Dias, C. B., Pinto, A.P., 2010. Removal of pharmaceuticals in microcosm constructed wetlands using Typha spp. and LECA. Bioresource Technology 101, 886-892.

Dordio, A.V., Estevao Candeias, A.J., Pinto, A.P. Teixeria da Costa, C., Palace Carvalho, A.J., 2009. Preliminary media screening for application in the removal of clofibric acid, carbamazepine and ibuprofen by SSF-constructed wetlands. Ecological Engineering 35, 290-302.

EC, 1976. Directive 76/769/ECC: Use of Certain Dangerous Substances and Preparations.” Off. J. L262 Final.

EC, 1991. Directive 91/271/EEC of 21 May 1991 concerning urban wastewater treatment. Off. J. L135, 40-52.

EC, 2000a. Directive 2000/60/EC of the European Parliament and of the Council of 23 October 2000 establishing a framework for Community action in the field of water policy. Off. J. L327, 1-73.

EC, 2000b. Endocrine disrupters website. How the European Comission uses the precautionary principle to tackle endocrine disrupters. [Available: http://ec.europa.eu/environment/endocrine/strategy/substances_en.htm [accessed 10 July 2013]].

EPA, 2010. United States Environmental Protection Agency. Treating contaminants of emerging concern. A literature review database. EPA-820-R-10-002. [Available: http://water.epa.gov/scitech/swguidance/ppcp/upload/cecliterature.pdf [accessed 23 May 2013]].

Farré, M., Kantiani, L., Petrović, M., Pérez, S., Barceló, D., 2012. Achievements and future trends in the analysis of emerging organic contaminants in environmental samples by mass spectrometry and bioanalytical techniques. Journal of Chromatography A 1259, 86-99.

Farré, M., Perez, S., Kantiani, L., Barceló, D., 2008. Fate and toxicity of emerging pollutants, their metabolites and transformafarretion products in the aquatic environment. Trends in Analytical Chemistry 27, 991-1007.

Fatta-Kassinos, D., Vasquez, M.I., Kümmerer, K., 2011. Transformation products of pharmaceuticals in surface waters and wastewater formed during photolysis and advanced oxidation processes -Degradation, elucidation of by products and assessment of their biological potency. Chemosphere 85, 693-709.

Faulwetter, J.L., Gagnon, V., Sundberg, C., Chazarenc, F., Burr, M.D., Brisson, J., Camper, A.K., Stein, O.R., 2009. Microbial processes influencing performance of treatment wetlands: a review. Ecological Engineering 35, 9871004.

FDA, 2011. Food and Drug Administration, Department of Health and Human Services, USA. Summary report on antimicrobials sold or distributed for use in food-producing animals. [Available: http://www.fda.gov/downloads/ForIndustry/UserFees/AnimalDrugUserFeeActADUFA/UCM338170.pdf [accessed 01 April 2013]].

Ferguson, P.J., Bernot, M.J., Doll, J.C., Lauer, T.E., 2013. Detection of pharmaceuticals and personal care products (PPCPs) in near-shore habitats of souther Lake Michigan. Science of the Total Environment 458-460, 187-196.

Fountoulakis, M.S., Terzakis, S., Chatzinotas, A., Brix, H., Kalogerakis, N., Manios, T., 2009. Pilot-scale comparison of constructed wetlands operated under high hydraulic loading rates and attached biofilm reactors for domestic wastewater treatment. Science of the Total Environment 407, 2996-3003.

Fram, M.S., Belitz, K., 2011. Occurrence and concentrations of pharmaceutical compounds in groundwater used for public drinking-water supply in California. Science of the Total Environment 409, 3409-3417. 
GAO, 2011. United States Government Accountability Office. Action Needed to Sustain Agencies' Collaboration on Pharmaceuticals in Drinking Water. Report to Congressional Requesters. [Available:

http://www.gao.gov/new.items/d11346.pdf [accessed 24 June 2013]].

García, J., Aguirre, P., Barragán, J., Mujeriego, R., Matamoros, V., Bayona, J.M., 2005. Effect of key design parameters on the efficiency of horizontal subsurface flow constructed wetlands: long-term performance pilot study. Ecological Engineering 25, 405-418.

García, J., Corzo, A., 2008. Water treatment with constructed wetlands: Handbook of design, construction and operation of subsurface flow wetlands Systems. Universitat Politècnica de Catalunya, Barcelona, Spain. [Available: http://upcommons.upc.edu/e-prints/bitstream/2117/2474/1/JGarcia_and_ACorzo.pdf [accessed 15 May 2010] (in Spanish)].

García, J., Ojeda, E., Sales, E., Chico, F., Píriz, T., Aguirre, P., Mujeriego, R., 2003a. Spatial variations of temperature, redox potential and contaminants in horizontal flow reed beds. Ecological Engineering 21, 129-142.

García, J., Rousseau, D.P.L., Morató, J. Lesage, E., Matamoros, V., Bayona, J.M., 2010. Contaminant removal processes in subsurface-flow constructed wetlands: a review. Critical Reviews in Environmental Science and Technology 40, 561-661.

Gómez, M.J., Herrera, S., Solé, D., García-Calvo, E., Fernández-Alba, A.R., 2012. Spatio-temporal evaluation of organic contaminants and their transformation products along a river basin affected by urban, agricultural and industrial pollution. Science of the Total Environment 420, 134-145.

González, S., Petrović, M., Barceló, D., 2007. Advanced liquid chromatography/mass spectrometry (LC-MS) methods applied to wastewater removal and the fate of surfactants in the environment. Trends in Analytical Chemistry 26, 116-124.

Gray, J. L., Sedlak, D.L., 2005. The fate of estrogenic hormones in an engineered treatment wetland with dense macrophytes. Water Environment Research 77, 24-31.

Halling-Sørensen, B., Nors Nielsen, S., Lanzky, P.F., Ingerslev, F., Holten Lützhøft, H.C., Jørgensen, E., 1998. Occurrence, fate and effects of pharmaceutical substances in the environment - A review. Chemosphere 36, 357393.

Headley, E.H., Davison, L., 2005. Treatment at different depths and vertical mixing within a 1-m deep horizontal subsurface-flow wetland. Ecological Engineering 25, 567-582.

Headley, T., Nivala, J., Kassa, K., Olsson, L., Wallace, S., Brix, H., van Afferden, M., Müller, R., 2013. Escherichia coli removal and internal dynamics in subsurface flow ecotechnologies: Effects of design and plants. Ecological Engineering, in press. doi: x.doi.org/10.1016/j.ecoleng.2013.07.062

Heberer, T., 2002. Occurrence, fate, and removal of pharmaceutical residues in the aquatic environment: a review of recent research data. Toxicology Letters 31, 5-17.

Hernando, M.D., Mezcua, M., Fernández-Alba, A.R., Barceló, D., 2006. Environmental risk assessment of pharmaceutical residues in wastewater effluents, surface water and sediments. Talanta 69, 334-342.

Hijosa-Valsero, M., Matamoros, V., Martín-Villacorta, J., Bécares, E., Bayona, J.M., 2010a. Assessment of full-scale natural systems for the removal of PPCPs from wastewater in small communities. Water Research 44, 1429-1439.

Hijosa-Valsero, M., Matamoros, V., Pedescoll, A., Martín-Villacorta, J., Bécares, E., García, J., Bayona, J.M., 2011b. Evaluation of primary treatment and loading regimes in the removal of pharmaceuticals and personal care products from urban wastewaters by subsurface-flow constructed wetlands. International Journal of Environmental Analytical Chemistry 91, 632-653.

Hijosa-Valsero, M., Matamoros, V., Sidrach-Cardona, R., Martín-Villacorta, J., Bécares. E., Bayona, J.M., 2010b. Comprehensive assessment of the design configuration of constructed wetlands for the removal of pharmaceuticals and personal care products from urban wastewaters. Water Research 44, 3669-3678.

Huang, Y., Ortiz, L., Aguirre, P., García, J., Mujeriego, R., Bayona, J.M., 2005. Effect of design parameters in horizontal flow constructed wetland on the behaviour of volatile fatty acids and volatile alkylsulfides. Chemosphere 59, 769777. 
Huber, M.M., Korhonen, S., Ternes, T.A., von Gunten, U., 2005. Oxidation of pharmaceuticals during water treatment with chlorine dioxide. Water Research 39, 3607-3617.

Ingerslev, F., Vaclavik, E., Halling-Sorensen, B., 2003. Pharmaceuticals and personal care products: a source of endocrine disruption in the environment. Pure and Applied Chemistry 75, 1881-1893.

Jana, B.B., 1998. Sewage-fed aquaculture: the Calcutta model. Ecological Engineering 11, 73-85.

Jelić, A., Gros, M., Ginebreda, A., Cespedes-Sánchez, R., Ventura, F., Petrović, M., Barceló, D., 2011. Occurrence, partition and removal of pharmaceuticals in sewage water and sludge during wastewater treatment. Water Research 45, 1165-1176.

Jurado, A., Vàzquez-Suñé, E., Carrera, J., López de Alda, M., Pujades, E., Barceló, D., 2012. Emerging organic contaminants in groundwater in Spain: a review of sources, recent occurrence and fate in a European context. Science of the Total Environment 440, 82-94.

Kadlec, R.H., 2009. Comparison of free water and horizontal subsurface treatment wetlands. Ecological Engineering 35, 159-174.

Kadlec, R.H., Wallace, S.D., 2009. Treatment Wetlands. $2^{\text {nd }}$ ed. CRC Press: Boca Raton, Florida. pp. 1016.

Kasprzyk-Hordern, B., Dinsdale, R.M., Guwy, A.J., 2009. The removal of pharmaceuticals, personal care products, endocrine disruptors and illicit drugs during wastewater treatment and its impact on the quality of receiving waters. Water Research 43, 363-380.

Katz, K., Inoue, T., Ietsugu, H., Koba, T., Sasaki, H., Miyaji, N., Kitagawa, K., Sharma, P.K., Nagasawa, T., 2013. Performance of six multi-stage hybrid wetland systems for treating high-content wastewater in the cold climate of Hokkaido, Japan. Ecological Engineering 51, 256-263.

Kayser, K., Kunst, S., 2005. Processes in vertical-flow reed beds: nitrification, oxygen transfer, and soil clogging. Water Science and Technology 51, 177-184.

Kim, S.D., Cho, J., Kim, I. S., Vanderford, B.J., Snyder, S.A., 2007. Occurrence and removal of pharmaceuticals and endocrine disruptors in South Korean surface, drinking and waste waters. Water Research 41, 1013-1021.

Kim, I., Yamashita, N., Tanaka, H., 2009. Performance of UV and UV/H2O2 processes for the removal of pharmaceuticals detected in secondary effluent of a sewage treatment plant in Japan. Journal of Hazardous Materials 166, 1134-1140.

Kimura, K., Hara, H., Watanabe, Y., 2005. Removal of pharmaceutical compounds by submerged membrane bioreactors (MBRs). Desalination 178, 135-140.

Klavarioti, M., Mantzavinos, D., Kassinos, D., 2009. Removal of residual pharmaceuticals from aqueous systems by advanced oxidation processes. Environment International 35, 402-417.

Knapp, C.W., Dolfing, J., Ehlert, P.A., Graham, D.W., 2010. Evidence of Increasing Antibiotic Resistance Gene Abundances in Archived Soils since 1940. Environmental Science and Technology 44, 580-587.

KNAPPE, 2008. Knowledge and Need Assessment on Pharmaceutical Products in Environmental Waters. FP7 Project. Final report. [Available: http://environmentalhealthcollaborative.org/images/KNAPPE_REPORT_FINAL.pdf]].

Knowles, P., Dotro, G., Nivala, J., García, J., 2011. Clogging in subsurface-flow treatment wetlands: occurrence and contributing factors. Ecological Engineering 37, 99-112.

Kolpin, D.W., Furlong, E.T., Meyer, M.T., Thurman, E.M., Zaugg, S.D., Barber, L.B., Buxton, H.T., 2002. Pharmaceuticals, Hormones, and Other Organic Wastewater Contaminants in U.S. Streams, 1999-2000: A National Reconnaissance. Environmental Science and Technology 36, 1202-1211.

Kosma, C.I., Lambropoulou, D.A., Albanis, T.A., 2010. Occurrence and removal of PPCPs in municipal and hospital wastewaters in Greece. Journal of Hazardous Materials 179, 804-817.

Kümmerer, K., 2009. The presence of pharmaceuticals in the environment due to human use -present knowledge and future challenges. Journal of Environmental Management 90, 2354-2366. 
Langergraber, G., Haberl, R., Laber, J., Pressl, A., 2003. Evaluation of substrate clogging processes in vertical flow constructed wetlands. Water Science and Technology 48, 25-34.

Lishman, L., Smyth, S.A., Sarafin, K., Kleywegt, S., Toito, J., Peart, T., Lee, B., Servos, M., Beland, M., Seto, P., 2006. Occurrence and reductions of pharmaceuticals and personal care proucts and estrogens by municipal wastewater treatment plants in Ontario, Canada. Science of the Total Environment 367, 544-558.

Liu, Z., Kanjo, Y., Mizutani, S., 2009. Removal mechanisms for endocrine disrupting compounds (EDCs) in wastewater treatment -physical means, biodegradation, and chemical advanced oxidation: a review. Science of the Total Environment 407, 731-748.

Llorens, E., Matamoros, V., Domingo, V., Bayona, J.M., García, J., 2009. Water quality improvement in a full-scale tertiary constructed wetland: Effects on conventional and specific organic contaminants. Science of The Total Environment 407, 2517-2524.

Loos, R., Locoro, G., Comero, S., Contini, S., Schwesig, D., Werres, F., 2010. Pan-European survey on the occurrence of selected polar organic persistent pollutants in ground water. Water Research 44, 4115-4126.

Loos, R., Gawlik, B.M., Locoro, G., Rimaviciute, E., Contini, S., Bidoglio, G., 2009. EU-wide survey of polar organic persistent pollutants in European river waters. Environmental Pollution 157, 561-568.

López-Serna, R., Petrović, M., Barceló, D., 2012. Occurrence and distribution of multi-class pharmaceuticals and their active metabolites and transformation products in the Ebro River basin (NE Spain). Science of the Total Environment 440, 280-289.

Masi, F., Martinuzzi, N., Bresciani, R., Giovannelli, L., Conte, G., 2007. Tolerance to hydraulic and organic load fluctuations in constructed wetlands. Water Science and Technology 56, 39-48.

Matamoros, V., Arias, C., Brix, H., Bayona, J.M., 2007. Removal of pharmaceuticals and personal care products (PPCPs) from urban wastewater in a pilot vertical flow constructed wetland and a sand filter. Environmental Science and Technology 41, 8171-8177.

Matamoros, V., Arias, C., Brix, H., Bayona, J.M., 2009a. Preliminary screening of small-scale domestic wastewater treatment systems for removal of pharmaceutical and personal care products. Water Research 43, 55-62.

Matamoros, V., Arias, C.A., Nguyen, L.X., Salvadó, V., Brix, H., 2012a. Occurrence and behavior of emerging contaminants in surface water and a restored wetland. Chemosphere 88, 1083-1089.

Matamoros, V., Bayona, J.M., 2006. Elimination of pharmaceuticals and personal care products in subsurface flow constructed wetlands. Environmental Science and Technology 40, 5811-5816.

Matamoros, V., Caselles-Osorio, A., García, J., Bayona, J.M., 2008a. Behaviour of pharmaceutical products and biodegradation intermediates in horizontal subsurface flow constructed wetland. A microcosm experiment. Science of the Total Environment 394, 171-176.

Matamoros, V., Duhec, A., Albaigés, J., Bayona, J.M., 2009b. Photodegradation of carbamazepine, ibuprofen, ketoprofen and 17 $\alpha$-ethinylestradiol in fresh and seawater. Water Air Soil Pollution 196, 161-168.

Matamoros, V., García, J., Bayona, J.M., 2005. Behavior of selected pharmaceuticals in subsurface flow constructed wetlands: A pilot-scale study. Environmental Science and Technology 39, 5449-5454.

Matamoros, V., García, J., Bayona, J.M., 2008b. Organic micropollutant removal in a full-scale surface flow constructed wetland fed with secondary effluent. Water Research 42, 653-660.

Matamoros, V., Salvadó, V., 2012. Evaluation of the seasonal performance of a water reclamation pond-constructed wetland system for removing emerging contaminants. Chemosphere 86, 111-117.

MedlinePlus, 2010. U.S. National Library of Medicine. [Available: http://www.nlm.nih.gov/medlineplus/ [accessed 28 August 2012]].

Mezcua, M., Gómez, M.J., Ferrer, I., Aguera, A., Hernando, M.D., Fernández-Alba, A.R., 2004. Evidence of 2,7/2,8dibenzodichloro-p-dioxin as a photodegradation product of triclosan in water and wastewater samples. Analytica Chimica Acta 524, 241-247. 
Miao, X.-S., Metcalfe, C.D., 2003. Determination of carbamazepine and its metabolites in aqueous samples using liquid chromatography-electrospray tandem mass spectrometry. Analytical Chemistry 75, 3731-3738.

Miège, C., Choubert, J.M., Ribeiro, L., Eusèbe, M., Coquery, M., 2009. Fate of pharmaceuticals and personal care products in wastewater treatment plants - Conception of a database and first results. Environmental Pollution 157, $1721-1726$.

Molle, P., Liénard, A., Boutin, C., Merlin, G., Iwema, A., 2005. How to treat raw sewage with constructed wetlands: an overview of the French systems. Water Science and Technology 51, 11-21.

Molle, P., Liénard, A., Grasmick, A., Iwema, A., 2006. Effect of reeds and feeding operations on hydraulic behavior of vertical flow constructed wetlands under hydraulic overloads. Water Research 40, 606-612.

Molle, P., Prost-Boucle, S., Liénard, A., 2008. Potential for total nitrogen removal by combining vertical flow and horizontal flow constructed wetlands: A full-scale experiment study. Ecological Engineering 34, 23-29.

Muñoz, I., Gómez-Ramos, M.J., Agüera, A., García-Reyes, J.F., Molina-Díaz, A., Fernández-Alba, A.R., 2009. Chemical evaluation of contaminants in wastewater effluents and the environmental risk of reusing effluents in agriculture. Trends in Analytical Chemistry 28, 676-694.

Naddeo, V., Meriç, S., Kassinos, D., Belgiorno, V., Guida, M., 2009. Fate of pharmaceuticals in contaminated urban wastewater effluent under ultrasonic irradiation. Water Research 42, 4019-4027.

Nivala, J., Headley, T., Wallace, S., Bernhard, K., Brix, H., van Afferden, M., Müller, R.A., 2013. Comparative analysis of constructed wetlands: the design and construction of the ecotechnology research facility in Langenreichenbach, Germany. Ecological Engineering, in press. doi: http://dx.doi.org/10.1016/j.ecoleng.2013.01.035.

Nivala, J., Hoos, M.B., Cross, C., Wallace, S., Parkin, G., 2007. Treatment of landfill leachate using an aerated, horizontal subsurface-flow constructed wetland. Science of the Total Environment 380, 19-27.

Nivala, J., Wallace, S., Headley, T., Kassa, K., Brix, H., van Afferden, M., Müller, R., 2012. Oxygen transfer and consumption in subsurface flow treatment wetlands. Ecological Engineering, in press. doi: http://dx.doi.org/10.1016/j.ecoleng.2012.08.028.

Oaks, J.L., Gilbert, M., Virani, M.Z., Watson, R.T., Meteyer, C.U., Rideout, B.A., Shivaprasad, H.L., Ahmed, S., Chudhry, M.J.I., Arshad, M., Mahmood, S., Ali, A., Khan, A.A., 2004. Diclofenac residues as the cause of vulture population decline in Pakistan. Nature 427, 630-633.

OECD, 2013. Organisation for Economic Co-operation and Development, Health Policy Studies. OECD Health Data: Health expenditure and financing: OECD Health Statistics (database). Pharmaceutical Pricing Policies in a Global Market, 2008. [Available: http://www.oecd-ilibrary.org/social-issues-migration-health/pharmaceuticalexpenditure-per-capita_pharmexpcap-table-en [accessed 24 March 2013]].

Park, N., Vanderford, B.J., Snyder, S.A., Sarp, S., Kim, S.D., Cho, J., 2009. Effective controls of micropollutants included in wastewater effluent using constructed wetlands under anoxic conditions. Ecological Engineering 35, 418-423.

Patra, S., Das, T.K., Ávila, C., Cabello, V., Castillo, F., Sarkar, D., Lahiri, S., Jana, B.B., 2012. Cadmium tolerance and antibiotic resistance in Escherichia coli isolated from waste stabilization ponds. Indian Journal of Experimental Biology 50, 300-307.

Pedescoll, A., 2010. Clogging in horizontal subsurface flow constructed wetlands (Doctoral thesis). Universitat Politècnica de Catalunya, Spain.

Pedescoll., A., Uggetti, E., Llorens, E., Granés, F., García, D., García, J., 2009. Practical method based on saturated hydraulic conductivity used to assess clogging in subsurface flow constructed wetlands. Ecological Engineering 35, 1216-1224.

Petrovic, M., Gonzalez, S., Barceló, D., 2003. Analysis and removal of emerging contaminants in wastewater and drinking water. Trends in Analytical Chemistry 22, 685-696.

Platzer, C., Mauch, K., 1997. Soil clogging in vertical flow reed beds: mechanisms, parameters, consequences and... solutions? Water Science and Technology 35, 175-182. 
Puigagut, J., Villaseñor, J., Salas, J.J., Bécares, E., García, J., 2007. Subsurface-flow constructed wetlands in Spain for the sanitation of small communities: a comparative study. Ecological Engineering 30, 312-319.

Quintana, J.B., Weiss, S., Reemtsma, T., 2005. Pathways and metabolites of microbial degradation of selected acidic pharmaceutical and their occurrence in municipal wastewater treated by a membrane bioreactor. Water Research 39, 2654-2664.

Reyes-Contreras, C., Hijosa-Valsero, M., Sidrach-Cardona, R., Bayona, J.M., Bécares, E., 2012. Temporal evolution in PPCP removal from urban wastewater by constructed wetlands of different configuration: A medium-term study. Chemosphere 88, 161-167.

Reyes-Contreras, C., Matamoros, V., Ruiz, I., Soto, M., Bayona, J.M., 2011. Evaluation of PPCPs removal in a combined anaerobic digester-constructed wetland pilot plant treating urban wastewater. Chemosphere 84, 12001207.

Rimkus, G.G., 1999. Polycyclic musk fragrances in the aquatic environment. Toxicology Letters 111, 37-56.

Rodríguez-Gil, J.L., Catalá, M., González, S., Romo, R., Valcárcel, Y., Segura, Y., Molina, R., Melero, J.A., Martínez, F., 2010. Heterogeneous photo-Fenton treatment for the reduction of pharmaceutical contamination in Madrid rivers and ecotoxicological evaluation by a miniaturized fern spores bioassay. Chemosphere 80, 381-388.

Rodríguez-Rojas, A., Rodríguez-Beltrán, J., Couce, A., Blázquez, J., 2013. Antibiotics and antibiotic resistance: a bitter fight against evolution. International Journal of Medical Microbiology, in press. doi: http://dx.doi.org/10.1016/j.ijmm.2013.02.004

Rosal, R., Rodríguez, A., Perdigón-Melón, J.A., Petre, A., García-Calvo, E., Gómez, M.J., Agüera, A., Fernández-Alba, A.R., 2010. Occurrence of emerging pollutants in urban wastewater and their removal through biological treatment followed by ozonation. Water Research 44, 578-588.

Santos, J.L., Aparicio, I., Callejón, M., Alonso, E., 2009. Occurrence of pharmaceutically active compounds during 1year period in wastewaters from four wastewater treatment plants in Seville (Spain). Journal of Hazardous Materials 164, 1509-1516.

Schulz, R., Peall, S.K.C., Hugo, C., Krause, V., 2001. Concentration, load and toxicity of spraydrift-borne azinphosmethyl at the inlet and outlet of a constructed wetland. Ecological Engineering 18, 239-245.

Schwarzenbach, R.P., Escher, B.I., Fenner, K., Hofstetter, T.B., Johnson, C.A., von Gunten, U., Wehrli, B., 2006. The Challenge of micropollutants in aquatic systems. Science 313, 1072-1077.

Shariati, F.P., Mehrnia, M.R., Salmasi, B.M., Heran, M., Wisniewski, C., Sarrafzadeh, M.H., 2010. Membrane bioreactor for treatment of pharmaceutical wastewater containing acetaminophen. Desalination 250, 798-800.

Singer, H., Muller, S., Tixier, C., Pillonel, L., 2002. Triclosan: occurrence and fate of a widely used biocide in the aquatic environment: field measurements in wastewater treatment plants, surface waters, and lake sediments. Environmental Science and Technology 36, 4998-5004.

Snyder, S.A., Adham, S., Redding, A.M., Cannon, F.S., DeCarolis, J., Oppenheimer, J., Wert, E.C., Yoon, Y., 2007. Role of membranes and activated carbon in the removal of endocrine disruptors and pharmaceuticals. Desalination 202, 156-181.

Song, H.-L., Nakano, K., Taniguchi, T., Nomura, M. and Nishimura, O., 2009. Estrogen removal from treated municipal effluent in small-scale constructed wetland with different depth. Bioresource Technology 100, 2945-2951.

Spieles, D.J., Mitsch, W.J., 2000. The effects of season and hydrologic and chemical loading on nitrate retention in constructed wetlands: a comparison of low- and high-nutrient riverine systems. Ecological Engineering 14, 77-91.

Stackelberg, P.E., Furlong, E.T., Meyer, M.T., Zaugg, S.D., Henderson, A.K., Reissman, D.B., 2004. Persistence of pharmaceutical compounds and other organic wastewater contaminants in a conventional drinking-watertreatment plant. Science of the Total Environment 329, 99-113.

Stein, O.R., Hook, P.B., Biederman, J.A., Allen, W.C., Borden, D.J., 2003. Does batch operation enhance oxidation in subsurface constructed wetlands? Water Science and Technology 48, 149-156. 
Stuart, M., Lapworth, D., Crane, E., Hart, A., 2012. Review of risk from potential emerging contaminants in UK groundwater. Science of the Total Environment 416, 1-21.

Tchobanoglous, G., Burton, F.L., 1991. Wastewater engineering: treatment, disposal and reuse, 3rd ed. Metcalf and Eddy (Eds.), McGraw-Hill: New York.

Teijón, G., Candela, L., Tamoh, K., Molina-Díaz, A., Fernández-Alba, A.R., 2010. Occurrence of emerging contaminants, priority substances (2008/105/CE) and heavy metals in treated wastewater and groundwater at Depurbaix facility (Barcelona, Spain). Science of the Total Environment 408, 3584-3595.

Ternes, T.A., Meisenheimer, M., McDowell, D., Sacher, F., Brauch, H.-J., Haist-Gulde, B., Preuss, G., Wilme, U., Zullei-Seibert, N., 2002. Removal of pharmaceuticals during drinking water treatment. Environmental Science and Technology 36, 3855-3863.

Thiere, G., Milenkovski, S., Lindgren, P.-E., Sahlén, G., Berglund, O., Weisner, S.E.B., 2009. Wetland creation in agricultural landscapes: biodiversity benefits on local and regional scales. Biological Conservation 142, 964-973.

Tietz, A., Kirschner, A., Langergraber, G. ,Sleytr, K., Haberl, R., 2007. Characterisation of microbial biocoenosis in vertical subsurface flow constructed wetlands. Science of the Total Environment 380, 163-172.

Torrens, A., Molle, P., Boutin, C., Salgot, M., 2009. Impact of design and operation variables on the performance of vertical-flow constructed wetlands and intermittent sand filters treating pond effluent. Water Research 43, 18511858.

Truu, M., Huhanson, J., Truu, J., 2009. Microbial biomass, activity and community composition in constructed wetlands. Science of the Total Environment 407, 3958-3971.

Tyroller, L., Rousseau, D.P.L., Santa, S., García, J., 2010. Application of the gas tracer method for measuring oxygen transfer rates in subsurface flow constructed wetlands. Water Research 44, 4217-4225.

UNDP, 2006. Human Development Report 2006. Beyond scarcity: Power, poverty and the global water crisis. United Nations Development Programme, New York. [Available: http://hdr.undp.org/en/media/HDR06-complete.pdf [accessed 20 July 2013]].

UNESCO, 2003. United Nations Educational, Scientific, and Cultural Organization. World Water Assessment Programme. Water for People, Water for Life - the United Nations World Water Development Report (Berghahn Books, Barcelona, 2003). [Available: http://sustainabledevelopment.un.org/content/documents/WWDR_english_129556e.pdf [accessed 03 May 2013]].

UNESCO, 2012. United Nations Educational, Scientific, and Cultural Organization. World Water Assessment Programme (WWAP). The United Nations World Water Development Report 4: Managing Water under Uncertainty and Risk. [Available: http://www.unesco.org/new/fileadmin/MULTIMEDIA/HQ/SC/pdf/WWDR4\%20Volume\%201Managing\%20Water\%20under\%20Uncertainty\%20and\%20Risk.pdf [accessed 20 May 2013]].

Vera, I., García, J., Sáez, K., Moragas, L., Vidal, G., 2011. Performance evaluation of eight years experience of constructed wetland systems in Catalonia as alternative treatment for small communities. Ecological Engineering 37, 364-371.

Verlicchi, P., Galletti, A., Petrovic, M., Barceló, D., Al Aukidy, M., Zambello, E., 2013. Removal of selected pharmaceuticals from domestic wastewater in an activated sludge system followed by a horizontal subsurface flow bed - Analysis of their respective contributions. Science of the Total Environment 454-455, 411-425.

Vymazal, J., 2002. The use of sub-surface constructed wetlands for wastewater treatment in the Czech Republic: 10 years experience. Ecological Engineering 18, 633-646.

Vymazal, J., 2005. Horizontal sub-surface flow and hybrid constructed wetlands systems for wastewater treatment. Ecological Engineering 25, 478-490.

Vymazal, J., 2009. The use of constructed wetlands with horizontal sub-surface flow for various types of wastewater. Ecological Engineering 35, 1-17.

Wallace, S.D., 2001. Patent: System for removing pollutants from water. United States: US 6,200,469 B1. 
Weedon, C.M., 2003. Compact vertical flow constructed wetland systems - first two years' performance. Water Science and Technology 48, 15-23.

Wiegel, S., Aulinger, A., Brockmeyer, R., Harms, H., Löffler, J., Reincke, H., Schmidt, R., Stachel, B., von Tümpling, W., Wanke, A., 2004. Pharmaceuticals in the river Elbe and its tributaries. Chemosphere 57, 107-126.

Wiessner, A., Kappelmeyer, U., Kuschk, P., Kästner, M., 2005. Influence of the redox condition dynamics on the removal efficiency of a laboratory-scale constructed wetlands. Water Research 39, 248-256.

Writer, J.H., Barber, L.B., Brown, G.K., Taylor, H.E., Kiesling, R.L., Ferrey, M.L., Jahns, N.D., Bartell, S.E., Schoenfuss, H.L., 2010. Anthropogenica tracers, endocrine disrupting chemicals, and endocrine disruption in Minnesota lakes. Science of the Total Environment 409, 100-111.

Yamamoto, H., Nakamura, Y., Moriguchi, S., Nakamura, Y., Honda, Y., Tamura, I., Hirata, Y., Hayashi, A., Sekizawa, J., 2009. Persistence and partitioning of eight selected pharmaceuticals in the aquatic environment: laboratory photolysis, biodegradation, and sorption experiments. Water Research 43, 351-362.

Yang, S., Carlson, K., 2004. Routine monitoring of antibiotics in water and wastewater with a radioimmunoassay technique. Water Research 38, 3155-3166.

Ying, G-G., Yu, X-Y., Kookana, R.S., 2007. Biological degradation of triclocarban and triclosan in a soil under aerobic and anaerobic conditions and comparison with environmental fate modelling. Environmental Pollution 150, 300305.

Yoon, Y., Westerhoff, P., Snyder, S.A., Wert, E.C., 2006. Nanofiltration and ultrafiltration of endocrine disrupting compounds, pharmaceuticals and personal care products. Journal of Membrane Science 270, 88-100.

Yu, J.T., Bouwer, E.J., Coelhan, M., 2006. Occurrence and biodegradability studies of selected pharmaceuticals and personal care products in sewage effluent. Agricultural Water Management 86, 72-80.

Zarate Jr., F.M., Schulwitz, S.E., Stevens, K.J., Venables, B.J., 2012. Bioconcentration of triclosan, methyl-triclosan, and triclocarban in the plants and sediments of a constructed wetland. Chemosphere 88, 323-329.

Zhang, J., Chang, V.W.C., Giannis, A., Wang, J.-Y., 2013. Removal of cytostatic drugs from aquatic environment: A review. Science of the Total Environment 445-446, 281-298.

Zhang, Y., Geissen, S.U., Gal, C., 2008. Carbamazepine and diclofenac: removal in wastewater treatment plants and occurrence in water bodies. Chemosphere 73, 1151-1161.

Zhang, D.Q., Gersberg, R.M., Hua, T., Zhu, J., Tuan, N.A., Tan, S.K., 2012a. Pharmaceutical removal in tropical subsurface flow constructed wetlands at varying hydraulic loading rates. Chemosphere 87, 273-277.

Zhang, D.Q., Gersberg, R.M., Zhu, J., Hua, T., Jinadasa, K.B.S.N., Tan, S.K., 2012b. Batch versus continuous feeding strategies for pharmaceutical removal by subsurface flow constructed wetland. Environmental Pollution 167, 124131.

Zhang, D.Q., Tan, S.K., Gersberg, R.M., Sadreddini, S., Zhu, J., Tuan, N.A., 2011. Removal of pharmaceutical compounds in tropical constructed wetlands. Ecological Engineering 37, 460-464.

Zhou, J.B., Jiang, M.M., Chen, B., Chen, G.Q., 2009. Emergy evaluations for constructed wetland and conventional wastewater treatments. Communication in Nonlinear Science and Numerical Simulation 14, 1781-1789.

Zorita, S., Mårtensson, L., Mathiasson, L., 2009. Occurrence and removal of pharmaceuticals in a municipal sewage treatment system in the south of Sweden. Science of the Total Environment 407, 2760-2770.

Zwiener, C., Frimmel, F.H., 2003. Short-term tests with a pilot sewage plant and biofilm reactors for the biological degradation of the pharmaceutical compounds clofibric acid, ibuprofen, and diclofenac. Science of The Total Environment 309, 201-211. 